\title{
Artificial miRNAs targeting CAG repeat expansion in ORFs cause rapid deadenylation and translation inhibition of mutant transcripts
}

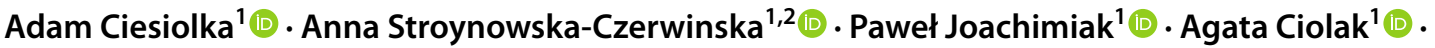

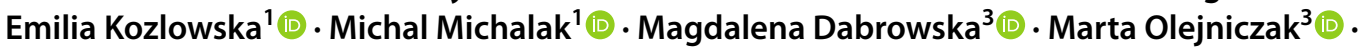 \\ Katarzyna D. Raczynska ${ }^{4,5}$ (D) Dominika Zielinska ${ }^{1}$. Magdalena Wozna-Wysocka' ${ }^{1}$ (1) - Wlodzimierz J. Krzyzosiak ${ }^{1}$ (1) . \\ Agnieszka Fiszer ${ }^{1}$ (D)
}

Received: 30 December 2019 / Revised: 1 July 2020 / Accepted: 9 July 2020 / Published online: 21 July 2020

(c) The Author(s) 2020

\begin{abstract}
Polyglutamine (polyQ) diseases are incurable neurological disorders caused by CAG repeat expansion in the open reading frames (ORFs) of specific genes. This type of mutation in the HTT gene is responsible for Huntington's disease (HD). CAG repeat-targeting artificial miRNAs (art-miRNAs) were shown as attractive therapeutic approach for polyQ disorders as they caused allele-selective decrease in the level of mutant proteins. Here, using polyQ disease models, we aimed to demonstrate how miRNA-based gene expression regulation is dependent on target sequence features. We show that the silencing efficiency and selectivity of art-miRNAs is influenced by the localization of the CAG repeat tract within transcript and the specific sequence context. Furthermore, we aimed to reveal the events leading to downregulation of mutant polyQ proteins and found very rapid activation of translational repression and $H T T$ transcript deadenylation. Slicer-activity of AGO2 was dispensable in this process, as determined in AGO2 knockout cells generated with CRISPR-Cas9 technology. We also showed highly allele-selective downregulation of huntingtin in human HD neural progenitors (NPs). Taken together, art-miRNA activity may serve as a model of the cooperative activity and targeting of ORF regions by endogenous miRNAs.
\end{abstract}

Keywords miRNA $\cdot$ CAG repeats $\cdot$ Polyglutamine diseases $\cdot$ Huntington's disease $\cdot$ Translational inhibition

This work is dedicated in the memory of Wlodzimierz Krzyzosiak, deceased in December 2017, who extensively developed research on repetitive sequences and his wife, Krystyna Krzyzosiak, deceased in May 2019, who greatly supported our scientific work.

Adam Ciesiolka and Anna Stroynowska-Czerwinska Joint Authors.

Wlodzimierz J. Krzyzosiak: Deceased.

Electronic supplementary material The online version of this article (https://doi.org/10.1007/s00018-020-03596-7) contains supplementary material, which is available to authorized users.

Agnieszka Fiszer

agnieszka.fiszer@ibch.poznan.pl

1 Department of Molecular Biomedicine, Institute of Bioorganic Chemistry, Polish Academy of Sciences, Noskowskiego 12/14, Poznan, Poland

2 Laboratory of Structural Biology, International Institute of Molecular and Cell Biology, Ks. Trojdena 4, Warszawa, Poland

$\begin{array}{ll}\begin{array}{l}\text { Abbreviations } \\ \text { 16CAG cell line }\end{array} & \begin{array}{l}\text { Stably expressing exon 1 of HTT with } \\ \text { 16 CAG repeats }\end{array} \\ \text { 98CAG cell line } & \begin{array}{l}\text { Stably expressing exon 1 of HTT with } \\ \text { 98 CAG repeats }\end{array} \\ \text { art-miRNAs } & \text { CAG repeat-targeting artificial miRNAs } \\ \text { ASO } & \text { Antisense oligonucleotide } \\ \text { ATN1 } & \text { Atrophin-1 } \\ \text { ATXN3 } & \text { Ataxin-3 } \\ \text { ATXN7 } & \text { Ataxin-7 } \\ \text { ddPCR } & \text { Digital droplet PCR } \\ \text { DRPLA } & \text { Dentatorubral-pallidoluysian atrophy }\end{array}$

3 Department of Genome Engineering, Institute of Bioorganic Chemistry, Polish Academy of Sciences, Noskowskiego 12/14, Poznan, Poland

4 Department of Gene Expression, Institute of Molecular Biology and Biotechnology, Adam Mickiewicz University in Poznan, Wieniawskiego 1, Poznan, Poland

5 Center for Advanced Technology, Adam Mickiewicz University, Wieniawskiego 1, Poznan, Poland 


$\begin{array}{ll}\text { Fluc } & \text { Firefly luciferase } \\ H T T & \text { Huntingtin } \\ \text { HD } & \text { Huntington's disease } \\ \text { ICC } & \text { Immunocytochemistry } \\ \text { iPSCs } & \text { Induced pluripotent stem cells } \\ \text { miRNA } & \text { MicroRNA } \\ \text { NP } & \text { Neural progenitor } \\ \text { ORF } & \text { Open reading frame } \\ \text { polyQ } & \text { Polyglutamine } \\ \text { RISC } & \text { RNA-induced silencing complex } \\ \text { SCA3 } & \text { Spinocerebellar ataxia type 3 } \\ \text { sgRNA } & \text { Small guide RNA } \\ \text { siRNA } & \text { Short interfering RNA } \\ \text { smFISH } & \text { Single-molecule fluorescent in situ } \\ & \text { hybridization } \\ \text { Rluc } & \text { Renilla } \text { Luciferase } \\ \text { NlucP } & \text { Nano luciferase with PEST domain } \\ \text { RT-qPCR } & \text { Quantitative reverse transcription PCR } \\ \text { UTR } & \text { Untranslated region }\end{array}$

\section{Introduction}

Non-coding RNAs (ncRNAs) are a large, diverse group of transcripts that do not contain information about protein sequence but mainly play a crucial role in the posttranscriptional regulation of gene expression. Examples of ncRNAs are short interfering RNAs (siRNAs) and microRNAs (miRNAs), which constitute a large family of short ( 21 nt) RNAs [1-4]. SiRNAs activate RNA-induced silencing complex (RISC) to carry out the AGO2-mediated cleavage of a transcript within a perfectly matched siRNA-mRNA duplex, followed by mRNA degradation [5]. In contrast, the miRNA strand guides the miRNA-induced silencing complex (miRISC) to interact with only partially complementary sequences within the transcripts in animal cells, causing translational inhibition and mRNA transcript decay following deadenylation [6-10].

Functional miRNA-binding sites are usually localized within the $3^{\prime}$ untranslated region (UTR) but might also be present within the open reading frame (ORF) [11-15] and 5'UTR [16-18]. These latter sites are considered as less functional than those in the $3^{\prime} \mathrm{UTR}$ as miRISCs cannot avoid collision with the scanning small ribosomal subunit and rapidly translocating ribosomes [19]. Importantly, the efficiency of the miRNA-mediated regulation of gene expression may depend on the number of miRNA-binding sites within the regulated target [20] and the distance between these sites [21]. The more target sites at an optimal distance on mRNA there are, the higher the observed inhibitory effect is, caused by cooperative interaction between miRISCs bound to neighboring sites [22].
SiRNAs and miRNAs, as negative regulators of gene expression, are often used in the development of therapeutic approaches. One of the examples are strategies for incurable and progressive neurodegenerative polyglutamine (polyQ) diseases which include Huntington's disease (HD), spinal bulbar muscular atrophy (SBMA), dentatorubral-pallidoluysian atrophy (DRPLA) or spinocerebellar ataxia (SCA) types 1, 2, 3, 6, 7 and 17 (Fig. 1a). These disorders are caused by the expansion of CAG repeat sequences within the ORFs of specific genes, so that the normal alleles contain 10-20 CAG repeats, whereas mutant alleles usually 40-70 CAG repeats. Due to a location of mutation within ORF, mutated gene encode protein with an expanded polyQ tract [23, 24].

One promising therapeutic approach is the elimination of mutant gene expression by directly targeting the mutation site in the transcript, i.e., the expanded CAG repeat tract $[25,26]$. In a series of studies from David Corey's and our groups, the effects of particular oligonucleotides, hereafter called C $\underline{A}$ r repeat-targeting artificial miRNAs (art-miRNAs), were tested in various polyQ disease models [27-40] (Table S1). The common feature of these oligonucleotides is the presence of specific mismatches in the interaction with the targeted CAG repeat tract, making these oligonucleotides similar to miRNAs. Allele-selective downregulation of mutant polyQ proteins by art-miRNAs most probably results from preferential activation of the silencing mechanism when multiple miRISCs are present on the expanded repeat tract. The targeted transcript level was less affected than the protein level as art-miRNAs did not induce the substantial mRNA cleavage typical of siRNAs [27, 28, 30]. Moreover, a study of the mechanism of action of art-miRNAs suggested cooperative silencing by miRISCs located on the expanded repeat tract, as revealed by dose-response experiments, and the involvement of AGO2 and GW182, as shown by RNA immunoprecipitation and siRNA-based knockdown experiments [30]. Intriguingly, the activities of art-miRNAs in various polyQ disease models differed significantly, and minor differences in oligonucleotide sequence largely affected the observed activity (Table S1). Therefore, we decided to investigate the details of the activated silencing process in the context of further development of this approach and as an example of miRNA-based targeting of ORF regions.

In this study, we aimed to elucidate the key factors affecting silencing efficiency of art-miRNAs and determine the mechanism of their action. For this purpose we used cells with endogenous mutant gene expression, including human neural progenitors (NPs), as well as we constructed several dedicated cellular models. We compiled the results of testing our most effective art-miRNA, A2 [33], to highlight the 
variance in its activity in different polyQ disease models. We show that allele-selectivity of art-miRNAs is determined by the localization of CAG repeat tract in ORF and strengthened by specific sequence of huntingtin (HTT) transcript. Moreover, we demonstrate that A2 induced rapid mRNA deadenylation and translation inhibition and $\mathrm{AGO} 2$ was not required in activated silencing mechanism.

\section{Materials and methods}

\section{Cell lines}

HEK 293T (American Type Culture Collection) and host Flp-In T-REx-293 cell lines (Thermo Fisher Scientific) were cultivated in Dulbecco's Modified Eagle's Medium (Sigma-Aldrich), containing 10\% fetal bovine serum (Biowest), penicillin-streptomycin solution (Sigma-Aldrich), $2 \mathrm{mM}$ L-glutamine (Sigma-Aldrich). Additionally, for 16CAG and 98CAG Flp-In T-REx-293 cell culture $100 \mu \mathrm{g} /$ $\mathrm{ml}$ hygromycin B (Thermo Fisher Scientific) and $5 \mu \mathrm{g} / \mathrm{ml}$ blasticidin S (Thermo Fisher Scientific) was supplemented. Patient-derived fibroblasts (Coriell Institute, SCA3 GM06153: 17/70 CAG repeats in ATXN3; HD GM04281: 17/68 CAG repeats in HTT, DRPLA GM13716: 16/68 CAG repeats in ATN1, SCA7 GM03561: 8/62 CAG repeats in ATXN7; and control line GM05565) were grown in Eagle's Minimal Essential Medium (Sigma-Aldrich) supplemented with $10 \%$ fetal bovine serum (Sigma-Aldrich), antibiotic-antimycotic solution (Sigma-Aldrich), $2 \mathrm{mM}$ GlutaMAX (Gibco) and MEM non-essential amino acids (Sigma-Aldrich).

Human neural progenitors (NPs) were derived from HD induced pluripotent stem cells (iPSC) ND42222 (19/109 CAG repeats in HTT) obtained from NINDS Human Genetics Resource Center (Coriell Institute). For neural induction STEMdiff SMADi Neural Induction Kit (STEMCELL Technologies) was used according to monolayer protocol, following manufacturer's instructions. Briefly, iPSC were grown in Essential 8 (Gibco) medium on Geltrex (Gibco) coated 6-well plate until 70-80\% confluence was reached. Then, iPSCs were dissociated to single cells by incubation with $0.5 \mathrm{mM}$ EDTA in PBS for $10 \mathrm{~min}$. Cells were counted using TC20 Automated Cell Counter (Bio-Rad) and resuspended at $1 \times 10^{6}$ cells $/ \mathrm{ml}$ density for seeding in STEMdiff Neural Induction Medium with SMADi and 10 nM Y-27632 (all from STEMCELL Technologies). For further cultivation cells were detached using Accutase (STEMCELL Technologies) and after third passage they were grown in STEMdiff Neural Progenitors Medium (STEMCELL Technologies).
Expression of SOX1, SOX2, PAX6, and NES markers was confirmed by ICC (Supplementary Figure S4A) and by RTqPCR (Supplementary Figure S4B). All cell lines were cultured at an appropriate cell confluence at $37{ }^{\circ} \mathrm{C}$ in $5 \% \mathrm{CO}_{2}$. Cell banks were stored in liquid nitrogen.

\section{RNA oligonucleotides}

All siRNA oligonucleotides (Table S2) were synthesized by Metabion or Future Synthesis, dissolved in water to $100 \mu \mathrm{M}$ concentration and stored at $-80{ }^{\circ} \mathrm{C}$. To obtain $20 \mu \mathrm{M}$ duplexes sense and antisense strands were diluted in annealing buffer, heated for $1 \min$ in $90^{\circ} \mathrm{C}$ and kept for gradual cooling at room temperature for $45 \mathrm{~min}$.

\section{Transfection}

Lipofectamine 2000 (Invitrogen) was used to transfect HEK 293T, Flp-In T-REx-293 cells and fibroblasts with plasmids and oligonucleotides, accordingly to the manufacturer's protocol. $24 \mathrm{~h}$ prior to transfection cells were plated after estimation of cell number. To optimize and monitor transfection efficiency control fluorescent BlockIT siRNA (Invitrogen) or control plasmid encoding GFP (System Biosciences) was used. Cells were harvested at specific time points indicated in figure legends. Briefly, HEK $293 \mathrm{~T}$ line (120,000 cells/well seeded into 24-well plate) was co-transfected with $100 \mathrm{ng}$ of plasmid of pmirGLO construct and $50 \mathrm{nM}$ oligonucleotide using $1.5 \mu \mathrm{l}$ Lipofectamine 2000 in $300 \mu \mathrm{l}$ medium. Generated Flp-In T-REx-293 lines (160,000 cells/well seeded into 12-well plate) were transfected with $100 \mathrm{nM}$ oligonucleotide using $4 \mu \mathrm{l}$ Lipofectamine 2000 in $1.2 \mathrm{ml}$ of medium. Transfection of NPs was performed at fourth or fifth passage using $2 \mu l$ of siPORT Amine (Ambion) per well of 6-well plate in $1 \mathrm{ml}$ of complete medium. After $3 \mathrm{~h}$ medium was replaced with fresh one and after next $24 \mathrm{~h}$ the medium was changed for the media lacking Y-27632. NPs were harvested using Accutase fixed $48 \mathrm{~h}$ post-transfection

\section{Protein isolation and western blot}

Cells were collected at specific time points for particular experiments (which are given in Figure legends), e.g. time points selected for most efficient downregulation of specific proteins in fibroblasts and NPs. Cell pellets were washed once with PBS and lysed with PB buffer $(60 \mathrm{mM}$ Tris-base, $2 \%$ SDS, $10 \%$ sucrose, $2 \mathrm{mM}$ PMSF). Next, the cell extract was heated in $95{ }^{\circ} \mathrm{C}$ for $5 \mathrm{~min}$ and protein concentration was estimated based on measurement at $280 \mathrm{~nm}$ using DeNovix 
spectrophotometer. Equal amounts $(\sim 30 \mu \mathrm{g})$ of total protein were diluted in loading buffer and heated in $95^{\circ} \mathrm{C}$ for 5 min and run on SDS-polyacrylamide gels: $5 \%$ stacking, $10 \%$ resolving gel in Tris/glycine/SDS buffer for ataxin-3 and luciferase detection; 3-8\% NuPAGE Tris acetate gels (Thermo Fisher Scientific) in XT Tricine buffer (Bio-Rad) with cooling in ice-water bath for atrophin-1 and huntingtin detection. Next, proteins were wet-transferred to nitrocellulose membrane (GE Healthcare) and specific primary (antiataxin-3, anti-huntingtin, anti-atrophin-1, anti-vinculin and anti-Fluc) and horseradish peroxidase-conjugated secondary antibodies (anti-rabbit or anti-mouse) were used. All antibodies used are given in Table S3. The immunodetection was performed using WesternBright Quantum HRP Substrate (Advansta). The chemiluminescent signals were scanned from membranes using GBOX documentation system (Syngene) and the bands were quantified using Gel-Pro Analyzer.

\section{RNA isolation, RT-qPCR and ddRT-PCR}

After cell lysis in TRI Reagent (ThermoFisher), Direct-zol RNA MiniPrep kit (ZymoResearch) or Total RNA Zol-Out kit (A\&A Biotechnology) was used for total RNA isolation. For Flp-In T-REx-293 cell lines, a fraction of lysates prepared in Cytoplasmic Lysis Buffer [PBS, 0.1\% NP40, cOmplete EDTA-free Protease Inhibitor Cocktail (Roche)] was mixed with four volumes of TRI Reagent for further isolation. The concentration of isolated total RNA was assessed by measurement at $260 \mathrm{~nm}$ using DeNovix spectrophotometer. Reverse transcription was performed using High-Capacity cDNA Reverse Transcription Kit (Applied Biosystems) and random hexamer primers (Promega), according to the manufacturer's protocols. RT-qPCR was performed using SsoAdvanced Universal SYBR Green Supermix (Bio-Rad) and CFX Connect Real-Time System (Bio-Rad), according to the manufacturer's protocols and established guidelines for qPCR. Digital droplet PCRs (ddPCRs) were prepared using DG8 cartridges and gaskets, QX200 Droplet Generation Oil and QX200 EvaGreen Digital PCR Supermix (BioRad) and performed on QX200 Droplet Digital PCR System (BioRad), according to the manufacturer's protocols. All primer sequences are listed in Table S4.

\section{Hill coefficient calculation}

The obtained results of an average relative protein level have been fitted by GraphPad Prism to the Hill equation curve $\left(y=a+(b-a) /\left[1+(K / x)^{N}\right]\right.$, where $x$ is oligonucleotide concentration, $y$ is relative protein expression, $a$ is minimal value of $y, b$ is maximal value of $y, K$ is fitting parameters and $N$ determines the slope of the curve and the value is the Hill coefficient, $\mathrm{nH}$ ).

\section{smFISH}

Probes, buffers and protocol from Stellaris RNA FISH technology (Biosearch Technologies) were used. Probes 3'-labelled with Quasar 670 dye were used for human HTT (cat \# SMF-20836-5) and ATXN3 (Custom Stellaris RNA FISH probes designed using online Stellaris probe designer, sequences are listed in Table S5), and with CAL Fluor 590 dye for GAPDH (cat \# SMF-2026-1). Cells were fixed in $4 \%$ paraformaldehyde in PBS for $20 \mathrm{~min}$ at RT, then prehybridized in Wash Buffer A containing 10\% formamide for $5 \mathrm{~min}$ at RT. Hybridization was performed in Hybridization Buffer with $10 \%$ formamide at $37{ }^{\circ} \mathrm{C}$ overnight. Washing was performed with Wash Buffer A for 30 min at $37^{\circ} \mathrm{C}$ and next with Wash Buffer B for 5 min at RT. SlowFade Diamond Antifade Mountant (Thermo Fisher Scientific) was used for nuclear staining. Images were captured with Leica DMI6000 inverted fluorescence microscope equipped with DFC360 FX camera. Excitation/emission filters sets were Leica A for DAPI, Chroma 49005 and 49009 for CAL Fluor 590 and Quasar670, respectively. To visually examine data, a maximum intensity z-projection of all of slices in each stack were created using ImageJ. Signals were simplistically attributed as nuclear based on DAPI staining. Quantification of individual RNA FISH spots was done using the StarSearch software (https://www.seas.upenn.edu/ rajlab/StarSearch /launch.html).

\section{Luciferase-based plasmids containing CAG repeat tracts}

The plasmids were generated on the basis of the pmirGLO Vector (Promega) encoding Firefly luciferase (Fluc) and Renilla luciferase (Rluc). CAG repeat tract sequences were inserted into Fluc gene, either downstream (" 3 'UTR" and " 3 'ORF" plasmids; between SalI and XbaI restriction sites) or upstream ("5'ORF" plasmids; between restriction sites for EcoRI and NdeI inserted in two steps using QuikChange II XL Site-Directed Mutagenesis Kit (Agilent Technologies)). "3'ORF" plasmid was generated by mutation of " 3 'UTR" plasmid in the Fluc gene STOP codon. ATXN3 and HTTspecific inserts with normal and mutant CAG repeat tracts were obtained by PCR using cDNA from fibroblast cell lines (SCA3 and HD) and primers with specific restriction sites. Short synthetic inserts (containing 17 CAG repeats and including specific restriction sites) were chemically synthesized (Sigma-Aldrich) and annealed for cloning. For longer synthetic inserts we used in vitro repeat expansion method known as Synthesis of Long Iterative Polynucleotide (SLIP) $[41,42]$ with the "17CAG" insert as initial template for the repeat tract expansion. After obtaining first plasmid 
with expanded CAG tract, we further modified a protocol and used two plasmids with various lengths of CAG tract in SLIP. This approach allowed for generating longer expansion at one step. Due to DNA polymerase slipping the lengths of mutated constructs are slightly different. Ligation of inserts with plasmids was performed using T4 Ligase (Promega) according to the manufacturer's procedure. Next, competent $\mathrm{DH} 5 \alpha E$. coli cells were transformed and plasmids were isolated using Endotoxin-free MidiPrep kit (Qiagen). Due to technical problems mutant synthetic inserts are not included for the set of " 5 'ORF" constructs. Sequences of DNA oligonucleotides used for cloning are given in Table S6.

\section{Flp-In T-REx-293 cell lines for inducible and stable expression of CAG repeat tracts}

All components of the designed dual-luciferase system were cloned into pcDNA5/FRT/TO vector (Invitrogen) for obtaining inducible expression in Flp-In T-REx-293 cell lines of either normal or mutant $H T T$ fragment. This vector was integrated into the genome via Flp recombinase-mediated DNA recombination at the FRT site. Sequences of Fluc and Nano luciferase with PEST domain (NlucP) were cloned from pmirGLO and pNL1.2 (Promega) vectors, respectively. A bidirectional inducible promoter system (BI-16) capable of reproducible coexpression of two proteins was constructed [43]. Additional SV40pA sequences were cloned from pNL1.2 (Promega) at respective sites. The full exon 1 of HTT containing either 16 or 98 CAG repeats was amplified in PCR and these inserts were cloned upstream of NlucP sequence to obtain expression of HTT-NlucP fusion gene. Sequences of DNA oligonucleotides used for cloning are given in Table S7. The pcDNA5/FRT/TO-based expression constructs and pOG44 vector were co-transfected (at 1:9 ratio) into Flp-In T-REx-293 host cells using Lipofectamine 2000, according to manufacturer's protocol. Selection of hygromycin-resistant monoclones that contain stably integrated expression cassette was performed using $100 \mu \mathrm{g} /$ $\mathrm{ml}$ hygromycin $\mathrm{B}$, according to manufacturer's protocols. Additional details on the DNA cloning procedure and the generation of these stable cell lines are given in Supplementary Methods.

\section{Luciferase assay}

For the results presented in the Figs. 2 and S2 assays were performed using Dual-Luciferase Reporter Assay System (Promega), accordingly to the manufacturer's protocol. Briefly, cells were lysed $24 \mathrm{~h}$ after transfection in Passive Lysis Buffer (Promega), followed by the luciferase activity measurement using Centro LB 960 Luminometer (Berthold Technologies). The Fluc measurement data was normalized firstly to Rluc signal in the sample, next to Fluc/Rluc signal ratio obtained in cells co-transfected with negative control (NTC, non-targeting siRNA) and particular plasmid, and finally to Fluc/Rluc signal ratio measured for cells treated with plasmid lacking CAG repeat insert and particular oligonucleotide.

For the results presented in the Figs. 4 and 5 cells were lysed using Cytoplasmic Lysis Buffer [PBS, 0.1\% NP40, cOmplete EDTA-free Protease Inhibitor Cocktail (Roche)] according to the REAP method [44]. Next, the lysates was used in the Nano-Glo Dual-Luciferase Reporter Assay System (Promega) and measured with Victor X4 Multilabel Plate Reader (Perkin Elmer), according to the manufacturer's instructions. Background values of NlucP and Fluc signals at $t=0 \mathrm{~h}$ were subtracted. Nluc signals for A2- or siHTT-treated cells were normalized to NlucP measurement obtained at specific time points for siRluc-treated cells. Finally, NlucP signal was normalized to Fluc signal in a respective sample.

\section{Polysome profiling}

The protocol was adapted from $[45,46]$. Briefly, $5 \times 10^{6}$ Flp-In T-REx-293 16 CAG or 98CAG cells were seeded into $55 \mathrm{~cm}^{2}$ plate in medium without antibiotics. After $24 \mathrm{~h}$ cells were transfected using selected oligonucleotides at final concentration of $100 \mathrm{nM}$. After additional $12 \mathrm{~h} H T T$ exogene expression was induced using $1 \mu \mathrm{g} / \mathrm{ml}$ doxycycline (SigmaAldrich) and after $3 \mathrm{~h} 100 \mu \mathrm{g} / \mathrm{ml}$ cycloheximide (SigmaAldrich) was added to inhibit translation elongation and fix ribosomes on transcripts. After 5 min of incubation at $37^{\circ} \mathrm{C}$ cells were washed with ice-cold PBS containing cycloheximide and harvested in $1.5 \mathrm{ml}$ of this buffer by scraping. Cells were collected by centrifugation at $300 \mathrm{rpm}$ for $5 \mathrm{~min}$ at $4{ }^{\circ} \mathrm{C}$ and lysed in $500 \mu \mathrm{l}$ ice-cold lysis buffer $(10 \mathrm{mM}$ HEPES pH 7,9; $1.5 \mathrm{mM} \mathrm{MgCl}_{2} ; 10 \mathrm{mM} \mathrm{KCl} ; 0.5 \mathrm{mM}$ DTT; $1 \%$ Triton $\mathrm{X}-100,100 \mu \mathrm{g} / \mathrm{ml}$ cycloheximide) containing also $100 \mu / \mathrm{ml}$ of RNasin (Promega). After $10 \mathrm{~min}$ incubation on ice lysates were centrifuged at $1500 \mathrm{~g}$ for $5 \mathrm{~min}$ at $4{ }^{\circ} \mathrm{C}$. Supernatant was collected and OD was measured at $260 \mathrm{~nm}$.

10-60\% sucrose gradients were prepared using Gradient Station (BioComp) in buffer containing $100 \mathrm{mM} \mathrm{KCl}$, $20 \mathrm{mM}$ HEPES pH 7.6; $5 \mathrm{mM} \mathrm{MgCl}{ }_{2}, 100 \mu \mathrm{g} / \mathrm{ml}$ cycloheximide; $5 \mu / \mathrm{ml} \mathrm{RNasin}$ and Protease Inhibitor Cocktail (Roche). 10 OD was loaded onto cooled sucrose gradients and centrifuged at $39,000 \mathrm{rpm}$ for $2 \mathrm{~h}$ and $40 \mathrm{~min}$ at $4{ }^{\circ} \mathrm{C}$ using ultracentrifuge and SW 41Ti rotor (Beckman Coulter) About twenty $0.5 \mathrm{ml}$ fractions were collected using Piston Gradient Fractionator (BioComp). Next, $0.5 \mathrm{ml}$ of TRI-reagent (Ambion) was added to each fraction and subsequently RNA was isolated, including treatment with DNase I. Equal volumes of total RNA were reverse transcribed and $H T T$ $N l u c P$ and $G A P D H$ expression levels were determined by qRT-PCR. 


\section{Poly(A) tail length measurements}

The analysis was performed based on a polyG/I extension method [47] using the Poly(A) Tail-Length Assay Kit (Thermo Fisher Scientific). In these experiments $5 \mu \mathrm{g} / \mathrm{ml}$ actinomycin-D (Sigma-Aldrich) was added to the medium of 16CAG and 98CAG Flp-In T-REx-293 cells to stop transcription. $200 \mathrm{ng}$ of isolated RNA from selected time points were taken for poly(A) tail length analysis that was performed following manufacturer's protocol. Specific primers used are listed in Table S4. For estimation of poly(A) tail lengths, a product obtained using gene-specific reverse primer was used as a reference. PCR products were analyzed on 2100 Bioanalyzer using DNA 1000 Kit (Agilent).

\section{Generation of AGO2 knockout and AG02(D597A) mutant stable cell lines and transient AGO2 overexpression}

CRISPR-Cas9-mediated AGO2 knockout and AGO2(D597A) mutant cell lines were established using previously generated Flp-In T-REx-293 98CAG cells. For AGO2 knockout Cas9_sg1 and Cas9_sg2 plasmids, encoding sgRNA1 and sgRNA2 which are specific for target sequences within exon 2 of $A G O 2$ gene, were used. Cas9_ $\operatorname{sg} 3$ encoding sgRNA3, binding to sequence within exon 14, was used for AGO2(D597A) mutant cell line. To generate these plasmids, sense and antisense DNA strands of $\mathrm{sgR}$ NAs were annealed and ligated into pSpCas9(BB)-2A-GFP (PX458) (Addgene) plasmid, digested with the FastDigest BpiI (Thermo Fisher Scientific). Chemically competent $E$. coli GT116 cells (InvivoGen) were transformed with the plasmids, plated onto ampicillin selection plates $(100 \mu \mathrm{g} /$ $\mathrm{ml}$ ampicillin) and incubated overnight at $37^{\circ} \mathrm{C}$. The plasmids were isolated using the Gene JET Plasmid Miniprep kit (Thermo Fisher Scientific) and analyzed by Sanger sequencing. For nucleofection Flp-In T-REx-293 98CAG cells were electroporated with the Neon Transfection System (Invitrogen). Briefly, $1 \times 10^{5}$ cells were harvested, resuspended in Buffer R and electroporated with $1 \mu \mathrm{g}$ of plasmid DNA (500 ng of each Cas9_sg1 and Cas9_sg2 plasmids) in $10 \mu \mathrm{l}$ tips using the following parameters: $1100 \mathrm{~V}, 20 \mathrm{~ms}$, two pulses. For AGO2(D597A) cell line generation, cells were electroporated with $1 \mu \mathrm{g}$ of plasmid DNA and $1 \mu \mathrm{l}$ of $100 \mu \mathrm{M}$ single-stranded donor oligonucleotide (ssODN) (IDT) harboring GAC to GCC codon change. Selection of clones is described in Supplementary Materials and Methods. The oligonucleotide sequences are included in Table S8. For AGO2 overexpression, $\mathrm{AGO} 2$ coding sequence was amplified using PCR from pIRESneo FLAG/HA Ago2 plasmid (Addgene, \#10822) [48] and cloned into pcDNA3.1(+) (Invitrogen) between HindIII/BamHI sites.

\section{Statistical analysis}

Analyses were performed using GraphPad Prism software. Two-tailed $p$ value $<0.05$ was considered significant and is depicted on the graphs by: $* 0.05>p>0.01$; $* * 0.01>p>0.001 ; * * * p<0.001$. All experiments which resulted in statistically-analyzed quantitative data were repeated at least three times (the exact number of biological replicates, $n$, is given in figure legends). Depending on the experimental setup specific statistical tests were used and are indicated in figure legends. The error bars in the graphs represent standard deviations.

\section{Results}

\section{A2-mediated silencing of different polyQ disease-related genes is varied}

A large set of art-miRNAs have been tested in fibroblasts derived from patients with several polyQ diseases (Table S1). We have now complemented our results obtained with the A2 oligonucleotide [33, 38, 39] and present a direct comparison of its activity when used at the same concentration in cell lines bearing similar repeat tract lengths in mutant alleles, i.e., 62-70 CAG repeats (Fig. 1a). Overall, we observed that the efficiency and allele-selectivity of A2 art-miRNA differed in various models of polyQ diseases. The highest degree of allele-selectivity was achieved for the downregulation of HTT and ATXN7, where mutant huntingtin and ataxin-7 proteins were lowered to $~ 20 \%$ of control level, without reduction in normal protein levels. For ataxin-7 we also observed significant increase in normal protein level after A2 treatment [39]. Normal ATN1 and ATXN3 alleles were more susceptible to downregulation, but levels of normal atrophin-1 and ataxin-3 was decreased by no more than $50 \%$ of the control level with a relatively high concentration of A2 (50 nM) (Fig. 1a). In all of the examined disease models, A2 caused an allele-selective decrease in mutant protein levels at a wider range of concentrations used, as shown in the DRPLA model example (Fig. 1b). Mutant atrophin-1 was downregulated with $20 \mathrm{nM} \mathrm{A2} \mathrm{to}$ less than $20 \%$ of the control level without a reduction in normal protein level. Additionally, we analyzed the activity of A2 at a very wide range of concentrations in HD and SCA3 models to assess potential cooperative activity, as was previously reported for other art-miRNAs [30, 31]. We obtained a Hill coefficient $(\mathrm{nH})$ value considerably $>1(\sim 1.7)$ what suggests cooperative activity of the silencing machinery for the downregulation of mutant huntingtin (Figs. 1c, S1A). On the other hand, among the models investigated, the ataxin-3 protein was decreased in the least allele-selective manner, and the obtained $\mathrm{nHs}$ suggest cooperative silencing of both 
(a)

\begin{tabular}{c|c|c|c} 
disease & gene & protein & $(\mathrm{CAG}) \mathrm{n}$ \\
\hline HD & HTT & huntingtin & $17 / 68$ \\
\hline DRPLA & ATN1 & atrophin-1 & $16 / 68$ \\
\hline SCA3 & ATXN3 & ataxin-3 & $17 / 70$ \\
\hline SCA7 & ATXN7 & ataxin-7 & $8 / 62$
\end{tabular}

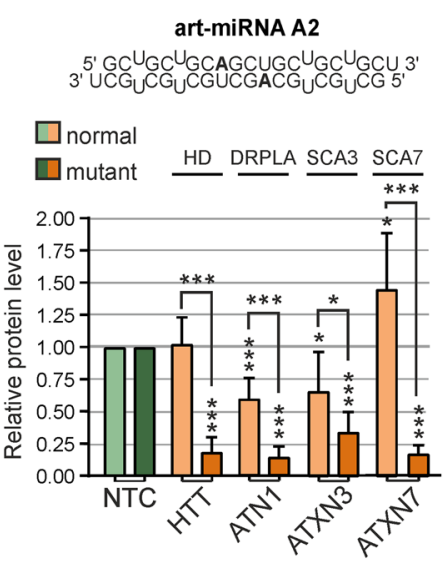

(d)

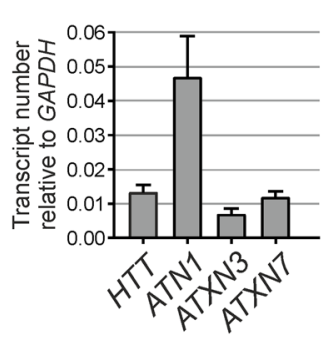

(b)
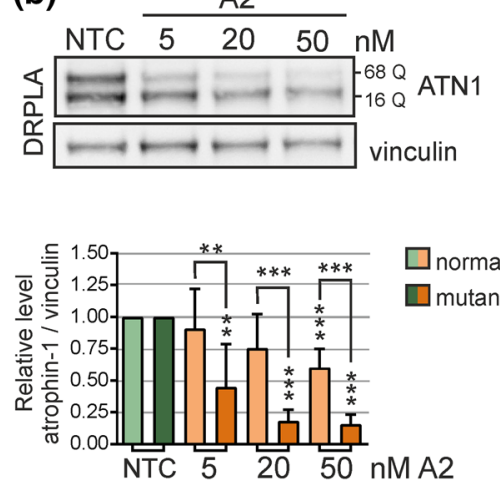

(c)

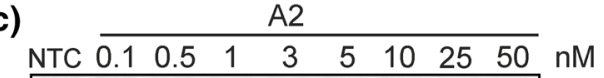

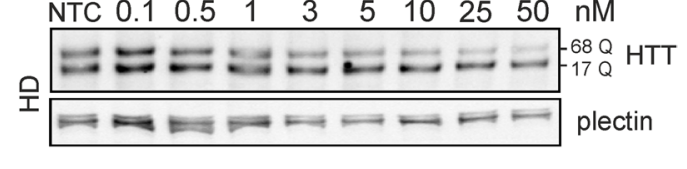

O normal

$\square$ mutant

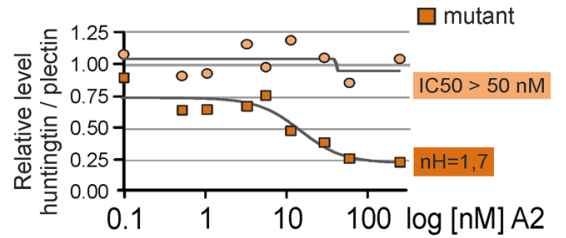

(e)

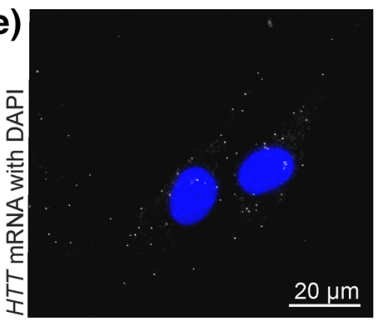

(f)

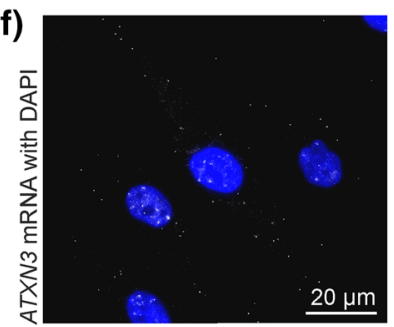

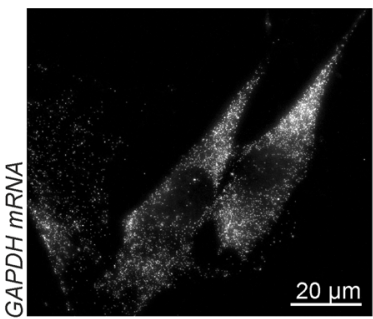
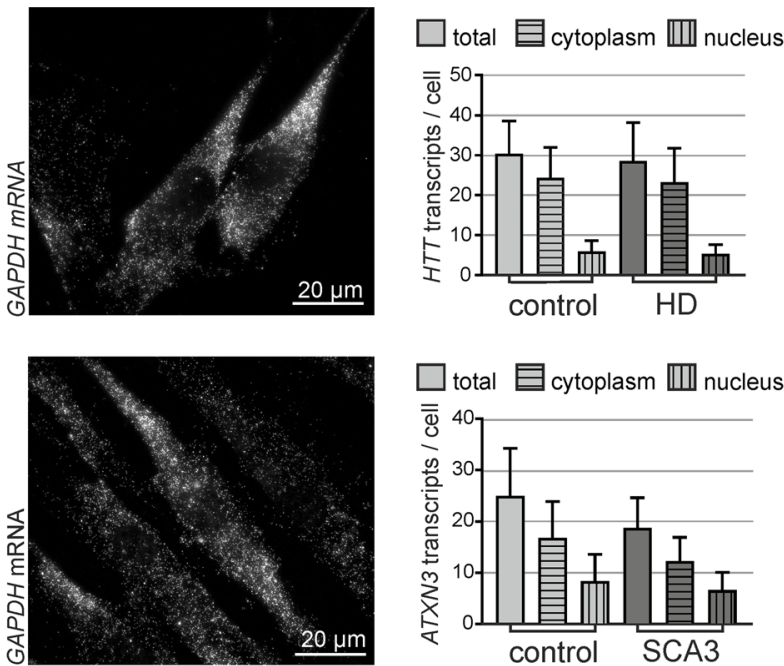

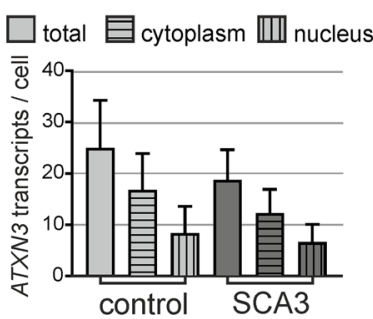

Fig. 1 A2 activity in patient-derived fibroblasts and the characteristics of targeted transcripts. a Upper panel: table with information about investigated models of polyQ diseases. In the last column CAG repeat tract lengths (normal/mutant allele), present in fibroblasts cells used, are given. Middle panel: sequence of art-miRNA A2 and predicted base-pairing of two strands within a duplex. Lower panel: results compiled from the western blot analysis showing HTT, ATN1, ATXN3 or ATXN7 protein levels in HD, DRPLA, SCA3 or SCA7-patient-derived fibroblasts, respectively, after transfection with $50 \mathrm{nM} \mathrm{A2.} \mathrm{Vinculin,} \mathrm{GAPDH} \mathrm{and} \mathrm{plectin} \mathrm{were} \mathrm{used} \mathrm{as} \mathrm{refer-}$ ence proteins. NTC-cells treated with non-targeting siRNA. The results of HTT and ATXN7 downregulation are from published studies $[33,39]$. The following statistical tests were used: one-sample $t$ test with a hypothetical value $=1$ for allele expression level; unpaired $t$ test with Welch's correction for comparisons of normal and mutant allele expression. $n=3 \mathbf{b}$ Western blot analysis of atrophin- 1 levels in DRPLA-patient-derived fibroblasts lysed $48 \mathrm{~h}$ after transfection with 5,20 or $50 \mathrm{nM} \mathrm{A2}$. NTC-cells treated with non-targeting siRNA.

the normal and mutant alleles by A2 (Fig. S1B). Overall, these and previous observations clearly show the targeted transcript-dependent activity of art-miRNAs.
Data were analyzed using one-way ANOVA (Bonferroni multiple comparisons test). $n=3$. $\mathbf{c}$ Western blot analysis of huntingtin levels in HD fibroblasts lysed $72 \mathrm{~h}$ after transfection with the indicated concentration of A2. The results are presented as dose-response curves that were used to calculate the indicated Hill coefficient. NTC-cells treated with non-targeting siRNA. See Figure S1A for more data. $n=3$ d Non-allele-specific quantification of HTT, ATN1, ATXN3 and ATXN7 transcripts with ddPCR. The results were obtained from two sets of cDNA from independent cultures of each of five fibroblast cell lines. See Figure S1C for more data. e, f Representative smFISH images for HTT (E) and ATXN3 (f) mRNAs in HD patientand SCA3 patient-derived fibroblasts, respectively. DAPI was used for nuclear staining. Middle panels: GAPDH transcripts detected in the same cells. Right panels: non-allele-specific quantification of $H T T$ and ATXN3 signals in healthy and patient-derived fibroblasts. Signals were counted from at least 50 cells. NTC used in experiments presented in this figure was BlockIT siRNA

\section{The cellular level of polyQ disease-related transcripts is relatively low}

To characterize several polyQ disease-related transcripts in more detail, we first performed their quantification in patient-derived fibroblast cells using ddPCR. The respective transcripts were present at very low levels relative to 
(a) HD I I RNA HTT

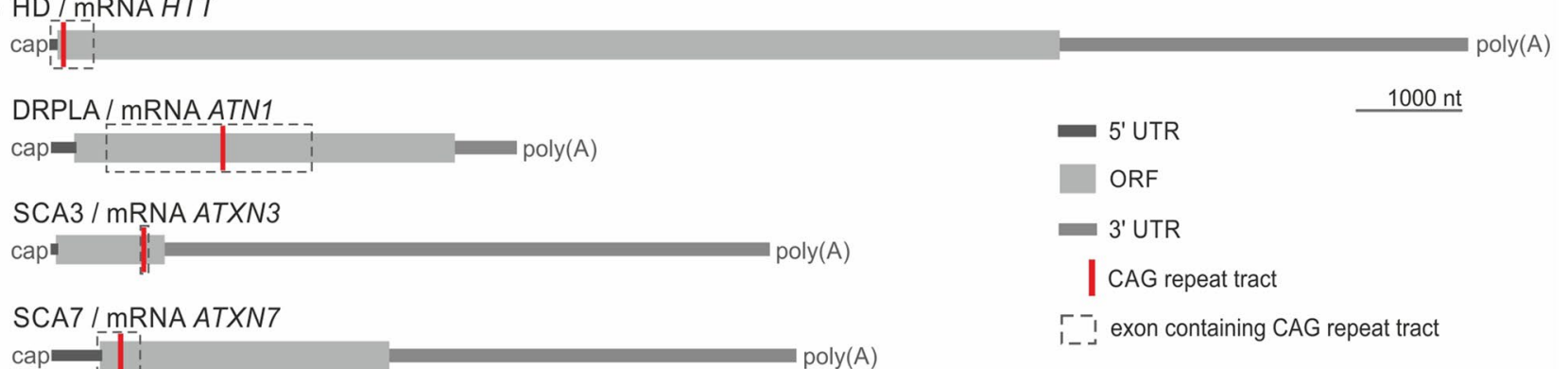

(b)

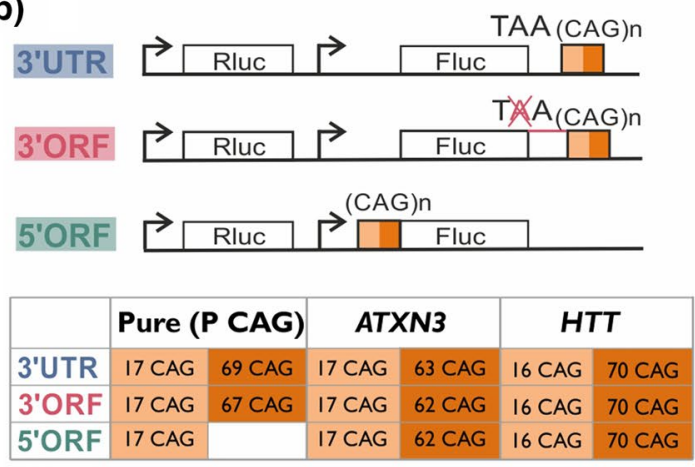

Fig. 2 Impact of repeat tract length, location and sequence surrounding the targeted region on efficiency of downregulation by A2. a Scheme of HTT (NM_002111.8), ATN1 (NM_001007026.2), ATXN3 (NM_004993.6) and ATXN7 (NM_000333.3) transcripts with CAG repeat tract locations, UTRs and ORFs marked. b Scheme of dualluciferase-based constructs containing the Fluc gene fused with the indicated CAG repeat tracts in various locations: the 3'UTR and 3' and $5^{\prime}$ sites of the ORF. The exact lengths of the tracts in constructs containing CAG repeats without ('Pure') or with gene-specific sur-

GAPDH, and similar expression levels of $H T T$ and $A T X N 7$, slightly lower ATXN3 levels and considerably higher ATN1 levels were observed (Fig. 1d). Five separately analyzed fibroblast cell lines showed some variation in transcript levels but without outstanding tendency for fibroblasts with the mutation in specific gene, e.g., the HTT mRNA level in HD fibroblasts (Fig. S1C).

In addition, we performed single-molecule fluorescent in situ hybridization (smFISH) for the precise quantification and visualization of selected transcripts in fibroblasts. Microscopic analyses showed approximately 30 HTT transcripts and approximately $20 A T X N 3$ transcripts per cell (Figs. 1e, f, S1D). Interestingly, the ratio of transcripts in the cytoplasm to those in the nucleus was approximately 4:1 and 2:1 for HTT and ATXN3, respectively. This suggests that larger cytoplasmic fraction of $H T T$ transcripts, in comparison to ATXN3 transcripts, is available for the activation of RISC-mediated processes in fibroblast cells. No substantial differences in specific mRNA copy number or localization were observed in the healthy cell line in comparison to

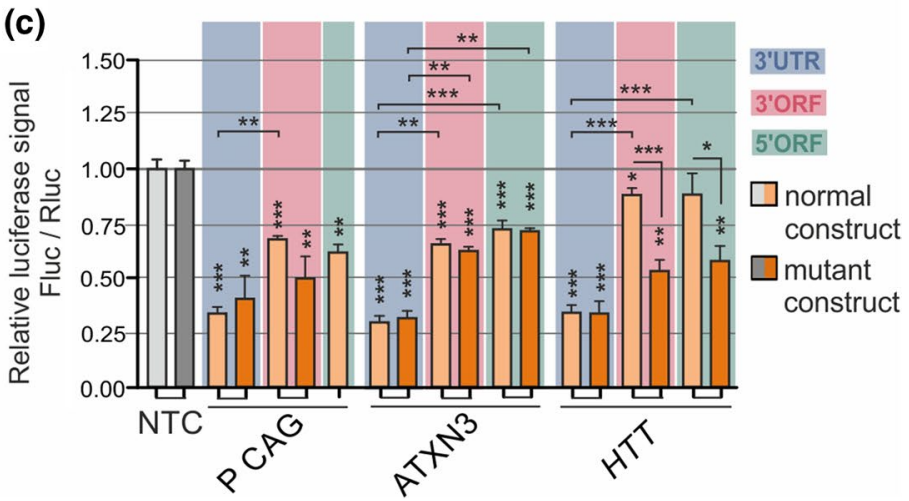

rounding sequences (from ATXN3 or HTT) are given in a table. c Luciferase assay performed $24 \mathrm{~h}$ after cotransfection of HEK 293T cells with $50 \mathrm{nM} \mathrm{A} 2$ and $100 \mathrm{ng}$ of the indicated plasmids. NTClight gray: cells treated with pmirGLO plasmid and non-targeting siRNA, dark gray: "5'ORF"-modified pmirGLO plasmid treated with non-targeting siRNA (signal normalization details are given in Materials and Methods). Data were analyzed using one-way ANOVA (with Bonferroni multiple comparisons test). $n=3$

mutant cell line (Figs. 1e, f, S1D). Therefore, we conclude that there are no significant differences in number or localization of normal vs. mutant variants of specific mRNA in human fibroblasts, although we were able to use only nonallele-specific quantification of transcripts by ddPCR and smFISH.

\section{The presence of the targeted region in an ORF and an $H T T$-specific flanking sequences improve the allele-selectivity of art-miRNAs}

The results in human fibroblasts demonstrated that activity of art-miRNAs is dependent on specific features of targeted transcripts (Fig. 1a). PolyQ disease-related transcripts differ considerably in the lengths of their ORFs and UTRs as well as the localization of CAG repeat tracts. In details, CAG repeat tract is located in $H T T$ and $A T X N 7$ at the $5^{\prime}$ end of the ORF, while in ATXN3 at the $3^{\prime}$ end of the ORF, and in ATN1 in the middle of the ORF (Fig. 2a). Therefore, we decided to elucidate how $\mathrm{CAG}$ repeat tract localization and sequences 
flanking CAG repeats influence silencing efficiency and allele preference by art-miRNAs. For this purpose, we generated pmirGLO-based plasmids encoding the Fluc gene, fused to a normal ( $\sim 17$ CAG repeats) or mutant ( 65 CAG repeats) tract, and Rluc as internal reference (Fig. 2b). The repeat tract was placed at two sides of the Fluc ORF: at the $H T T$-like 5' side ("5'ORF") or at the ATXN3-like 3' side ("3'ORF"), as well as in the 3 'UTR, which is a typical region for miRNA-binding sites. Inserts contained either pure CAG repeats (P CAG) or $\sim 50 \mathrm{nt}-$ long HTT or ATXN3 mRNA sequences flanking both sites of the CAG repeat tract, giving a total of 17 constructs (Fig. 2b).

First, we confirmed the expression of fusion proteins in HEK 293T cells (Fig. S2A). Next, we co-transfected the designed plasmids with selected oligonucleotides (artmiRNAs, siRNA targeting Fluc-siFluc or non-targeting siRNA-NTC) and performed a dual-luciferase assay. Typical siRNA, siFluc, caused efficient reduction of expression of all the constructs, to $\sim 10 \%$ of the control level, regardless the location of the target site (Fig. S2C). In contrast, for A2 we observed varied activity for particular constructs (Fig. 2c). The most prominent downregulation of Fluc by A2 was obtained for the targeted sequence location in the " 3 'UTR" constructs (Fig. 2c, bars with blue background). The luciferase signal was decreased to $\sim 35 \%$ of the control level regardless of repeat tract length and the sequence flanking CAG repeats. Downregulation of constructs expression with the target sequence localized in the ORF of Fluc was less efficient (Fig. 2c, bars with a red and green background), however for constructs containing HTT flanking sequence (both " 3 'ORF" and " 5 'ORF") we observed significant alleleselectivity of A2 activity. In these cases, expression of the mutant construct was decreased to $\sim 50 \%$ of the control level, whereas normal construct expression remained unchanged or decreased to only $~ 90 \%$ of the control level (Fig. 2c). Similar results were obtained for the other art-miRNAs analyzed: A4, G2 and G4 (Fig. S2b, c). Together, these observations demonstrate that the allele-selectivity of art-miRNAs was achieved only for constructs with $H T T$-specific sequences. In agreement with the results obtained in patient-derived fibroblasts (Fig. 1a), we conclude that better art-miRNAs allele-selectivity of $H T T$ downregulation in comparison to $A T X N 3$, is a combination of two effects: (1) increased downregulation of the mutant $H T T$ allele as compared to mutant ATXN3 and (2) decreased silencing of the normal HTT allele in comparison with normal ATXN3.

We also considered additional features of HTT and ATXN3 mRNAs that could affect the discrepancy in artmiRNA allele-selectivity in HD and SCA3 models (Supplementary Text). For example, the presence of rare codons, upstream to miRNA-binding site, was shown to improve the efficiency of miRNA silencing for targets present in ORFs, possibly due to the decreased rate of translation [49].
Therefore, we analyzed the codon usage values in $H T T$ and ATXN3 transcript sequences upstream of the CAG repeat tracts (Fig. S3), but no significant differences were found for these mRNAs in this aspect (Supplementary Text).

\section{A2 and siHTT caused a decrease in HTT mRNA in the cytoplasm of HD NPs}

To investigate A2 activity in a more disease-relevant cell type, we included an additional model of human NP cells, derived from iPSCs. As A2 acted with high allele-selectivity for HTT silencing, we generated HD NPs. First, we characterized this cell line for the expression of neural stem cells markers (Fig. S4a, b) and optimized oligonucleotide delivery (Fig. S4c). Next, we investigated the efficiency of $H T T$ expression silencing and changes in transcript abundance in HD NPs after transfection with $H T T$-specific siRNA (siHTT) or A2 art-miRNA. Similarly to results in HD fibroblasts (Fig. 1a), in HD NPs A2 allele-selectively downregulated mutant proteins to $\sim 30 \%$ of the control level, without reduction in normal protein level, whereas siHTT decreased both alleles of the huntingtin protein to $\sim 25 \%$ of the control level (Fig. 3a). Next, we performed a microscopic observation of endogenous HTT transcripts targeted with A2. Using nonallele-selective smFISH, we observed a cytoplasm-specific decrease in the huntingtin transcript number by $\sim 45 \%$ after treatment with $\mathrm{A} 2$ and a more substantial reduction by $\sim 70 \%$ after treatment with siHTT (Fig. 3b, c). This observation stays in agreement with the classical model of RISC activity in cytoplasm. Cellular localization of targeted transcript could affect the efficiency of its targeting by miRNA or siRNAs. In recent study, a larger fraction of $H T T$ transcripts was detected in the nuclei of healthy human neuronal cells compared to non-neuronal cells [50]. In agreement with this observation, we also observed an increased ratio of nuclear to cytoplasmic HTT mRNAs in NPs, relative to fibroblasts (Figs. 1e, 3c). It is worth to notice that, after treatment with A2, we did not observe the retention of transcripts in the nucleus or cytoplasmic aggregation of mRNAs, that could result in decreased huntingtin synthesis and suggesting additional mechanisms of art-miRNA activity. Taken together, the results obtained in HD NPs show the therapeutic potential of A2, as its allele-selective activity was achieved not only in patient-derived fibroblasts but also in the neuronal cell line.

\section{Kinetic analysis of transcript and protein downregulation shows the early events of translation inhibition induced by $A 2$}

To verify crucial factors affecting art-miRNAs activity and mechanistic details, we decided to include additional models with the exogenous expression of the targeted transcripts. 
Fig. 3 A2 activity in human HD neural precursors. a Western blot analysis of huntingtin allele levels in HD NPs lysed $48 \mathrm{~h}$ after transfection with $100 \mathrm{nM}$ non-targeting siRNA (NTC, BlockIT siRNA), siHTT (siRNA for HTT) or the art-miRNA A2. $n=4$. b Representative images showing the smFISH-based detection of $H T T$ and GAPDH mRNAs in non-treated (NT) HD NP cells and HD NP cells treated with $100 \mathrm{nM}$ fluorescent siRNA (BlockIT), non-targeting siRNA (NTC, siRluc), siHTT or A2 Cells were fixed $48 \mathrm{~h}$ after transfection with the indicated oligonucleotides. c Quantification of smFISH images for the experiments described in $\mathbf{b}$. Signals were counted from at least 200 cells for each treatment. Data were analyzed using oneway ANOVA (with Bonferroni multiple comparisons test) (a)
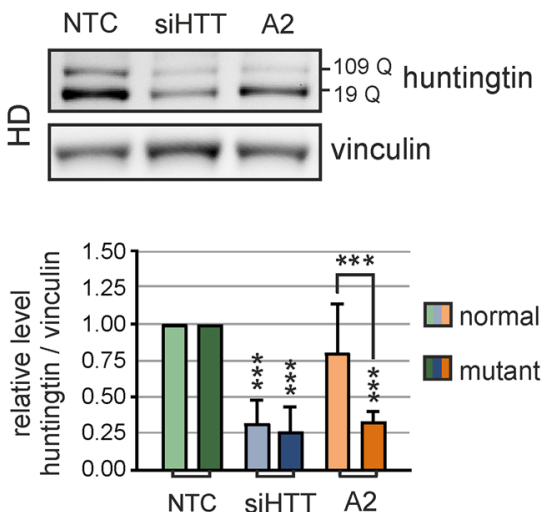

(b)

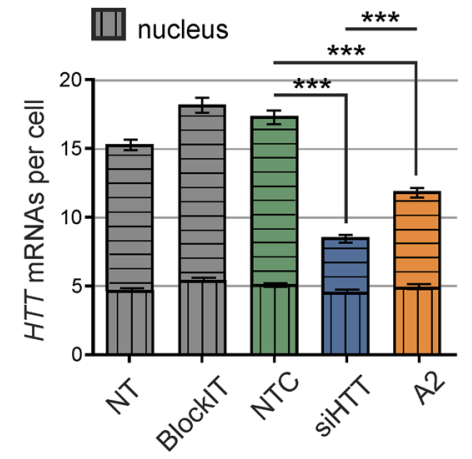

(c)
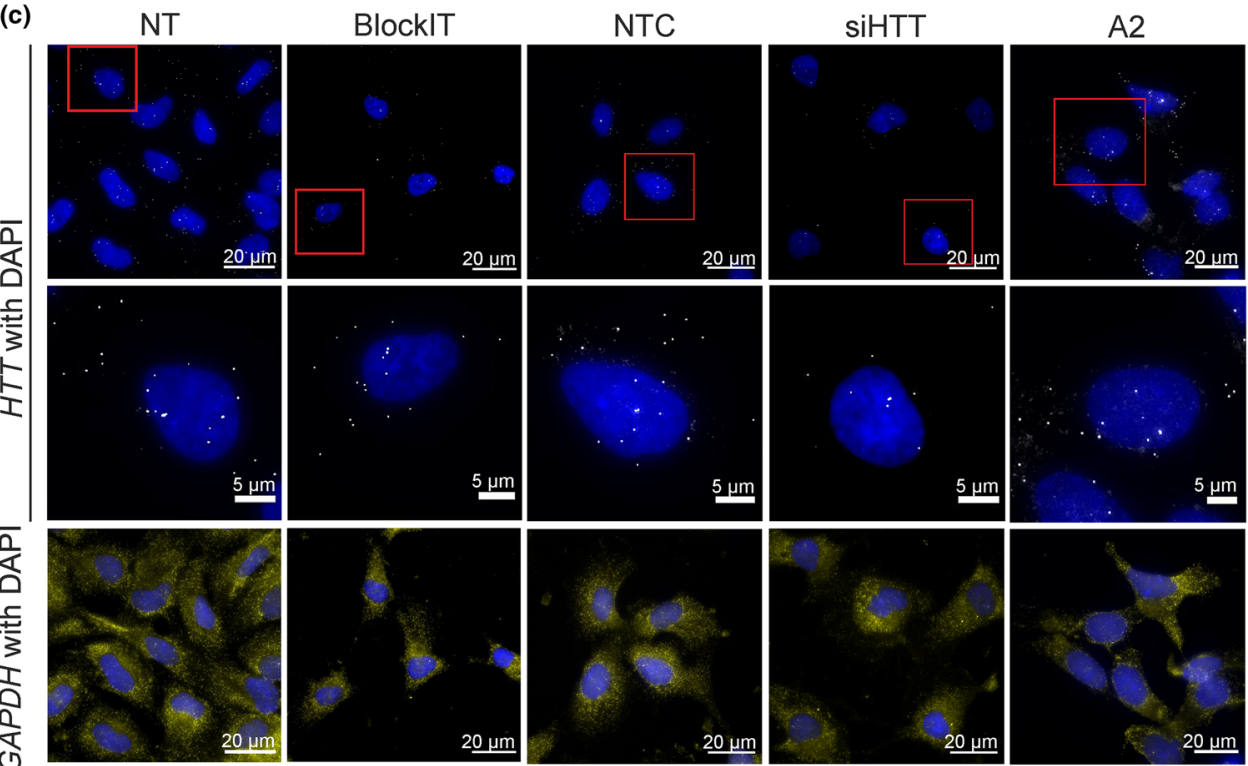

For this purpose, we designed a dual-luciferase system for the inducible expression of HTT reporters. We generated Flp-In T-REx-293 cell lines stably expressing exon 1 of HTT (with 16 or 98 CAG repeats, hereafter called "16CAG" and "98CAG" cell lines, respectively) fused with the NlucP reporter, named HTT-NlucP (Fig. 4a). Fluc expression was used as a normalization control, and both reporters were placed under a bidirectional doxycycline-inducible promoter. First, we confirmed the similar expression of the reporters and non-significant Bl-16 promoter leakage in the absence of doxycycline (Fig. S5A, B). Next, we transfected the 16CAG and 98CAG cell lines with the art-miRNA A2, siRNA specific for HTT, siHTT, or non-targeting siRNA, followed by induction of reporter expression and subsequent analysis of the transcript and protein levels at particular time points (Fig. 4b).

The kinetics of HTT reporter transcript and protein downregulation by A2 were clearly different in the 16CAG and 98CAG cell lines (Fig. 4c). For the mutant HTT reporter transcript, we observed a maximum of $\sim 50 \%$ downregulation starting $3 \mathrm{~h}$ after induction, whereas for the normal HTT reporter transcript, we detected only a slight decrease (Fig. 4c, upper panel). In contrast to the transcript levels, repression of the HTT-NlucP protein by A2 was more prominent, and the mutant protein level was decreased up to $\sim 30 \%$, while the normal protein was decreased up to $\sim 60 \%$ of the control level at selected time points (Fig. 4c, lower panel). Interestingly, at early time points (up to $2 \mathrm{~h}$ postinduction), A2 significantly lowered only the level of mutant protein, suggesting that translational repression preceded mRNA decay in the allele-selective inhibition of the mutant $H T T$ allele. As a reference for the typical RNAi mechanism, we performed the same analysis with siHTT. We observed rapid transcript and protein downregulation with no apparent difference in activity towards the normal and mutant alleles (Fig. 4d), suggesting the AGO2-mediated cleavage of both transcripts and, as a result, a decrease in the protein levels. 


\section{A2 causes a shift of mutant transcripts from heavy polysome fractions}

To assess translation inhibition caused by art-miRNA in more detail, we performed polysome profiling analysis of HTT reporter transcripts. The $98 \mathrm{CAG}$ and $16 \mathrm{CAG}$ cell lines were treated with A2 or control siRNA, and lysates were prepared $3 \mathrm{~h}$ after the induction of luciferase expression (Fig. 4b, e, representative UV absorbance profiles, including a profile following disruption with EDTA, are shown in Fig. S6a). In 98CAG cells A2 caused a statistically significant shift in $H T T$ reporter transcript distribution in the analyzed fractions, as referred to non-targeting siRNA treatment. We observed an approximately two-fold change in mutant HTT-NlucP transcript abundance in selected fractions, i.e., increased cosedimentation with $40 \mathrm{~S}, 60 \mathrm{~S}, 80 \mathrm{~S}$ and first light polysome fraction and decreased cosedimentation with heavier polysomes, as compared to the treatment with control siRNA (Fig. 4e, upper panels). This results suggest that A2 inhibited mutant HTT-NlucP translation at initiation and/or early elongation step. In these experiments, some $H T T-N l u c P$ transcripts remained associated with heavier polysomes after A2 treatment, probably because not all HTT reporter transcripts were bound by this art-miRNA. Our conclusions are supported by analogous control experiments performed in the 16CAG cell line which results did not show any significant difference in the cosedimentation of $H T T$ NlucP transcripts across the collected fractions between A2- and control siRNA-treated cells (Fig. 4e, lower panels). Moreover, as expected, no significant changes in Fluc expression relative to GAPDH expression were observed in experiments using both, 98CAG and 16CAG cell lines (Fig. S6b). Together, we conclude that observed translation inhibition occurred very rapidly and efficiently for mutant transcript as a result of A2 activity.

\section{A2 induces rapid shortening of the targeted mRNA poly(A) tail}

We aimed to explain in more detail the observation that mutant $H T T$ reporter protein level was decreased after A2 treatment already at early time points $(1-2 \mathrm{~h})$ after induction, without a change in the level of its transcript (Fig. 4c). This can be explained as the effect of direct translation inhibition or transcript deadenylation, which in turn results in reduced translation due to disrupted transcript circulation. To verify the latter mechanism, we performed transcription pulse-chase experiment and examined the length of poly(A) tails in $H T T$ reporter transcripts using poly $\mathrm{G} / \mathrm{I}$ extension followed by resolution of the PCR products in a microfluidic chip (Fig. S7a). In details, after transfection of the 98CAG and 16CAG cell lines with A2 or control siRNA, we induced expression of the HTT reporter for $1 \mathrm{~h}$, stopped the transcription and then analyzed poly(A) tail length profiles at three time points (Fig. 4b, f).

In the 98CAG cell line, A2 caused significant deadenylation of HTT-NlucP transcript already at the $60 \mathrm{~min}$ time point, when a substantial pool of $H T T$ reporter transcript deadenylation intermediates with a short ( 30 A) poly(A) tail appeared (Fig. 4f, upper panels). The formation of transcripts with shortened poly(A)-tails further accelerated at the $80 \mathrm{~min}$ and $240 \mathrm{~min}$ time points (Fig. 4f, upper panels). In contrast, we did not observe these deadenylation intermediates at even the 240 min time point after treatment of the 98CAG cell line with control siRNA. Analogous experiments in the 16CAG cell line showed no significant difference in the poly(A) tail length profiles of A2- and control siRNA-treated cells at the 60 and 80 min time points and only a slight difference at the latest $240 \mathrm{~min}$ time point (Fig. 4f, lower panels). In both cell lines and following treatment with A2 and control siRNA, we observed significant changes in the length of the poly(A) tail at $240 \mathrm{~min}$ compared to that at earlier time points (Fig. S7b), indicating events typical of transcript decay after transcription arrest. Taken together, A2 caused rapid deadenylation only of mutant HTT-NlucP transcript, suggesting crucial role of this process in the art-miRNA-mediated repression. Deadenylation is expected to lead to mutant transcript degradation observed at later time points (3-24 h) (Fig.4c).

\section{AG02 is dispensable for the A2-mediated silencing of $H T T$ expression}

Our next step was to elucidate the role of AGO2 in artmiRNA mechanism. We wanted to determine if AGO2 presence or the activity of its catalytic subunit is required for art-miRNAs-mediated silencing. To verify this, we modified the 98CAG cell line using CRISPR-Cas9 technology. We created homozygous cell lines in which $A G O 2$ gene was knocked out (AGO2del) or a cleavage-deficient AGO2/ D597A protein was expressed (AGO2mut) (Fig. S8a, b). The D597A mutation in AGO2 is known to abolish RNA cleavage without affecting efficiency of siRNA binding or translational repression [51, 52]. Two sgRNAs were designed to knock out AGO2 by deletion of a gene fragment in exon 2 leading to premature STOP codons (Fig. S8a, b), whereas an approach using one sgRNA and a donor template containing a specific nucleotide mutation was used to introduce a catalytic mutation in AGO2 (Fig. S8c, d). We selected the final clones based on the results of DNA sequencing (Fig. S8b, d) and AGO2 immunoblotting (Fig. 5b).

To analyze the requirement of AGO2 in A2 and siHTT activities, we analyzed both the transcript and protein levels of the mutant HTT reporter in 98CAG-AGO2mut and -AGO2 del cell lines. In addition, we performed rescue experiments and transfected cell lines with plasmids encoding WT 
(a)

'16CAG' cell line

poly(A) $=$ FLuc

'98CAG' cell line

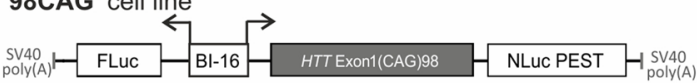

(c)
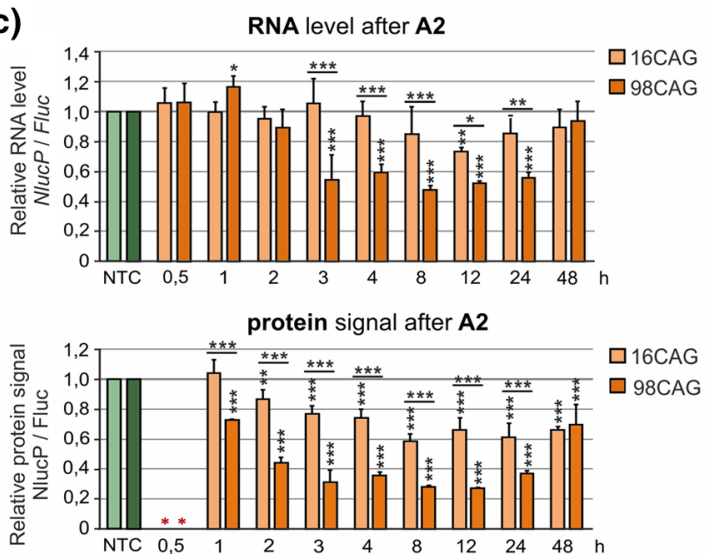

(b)

(b)
transfection
control siRNA (NTC)

(d)

RNA level after siHTT
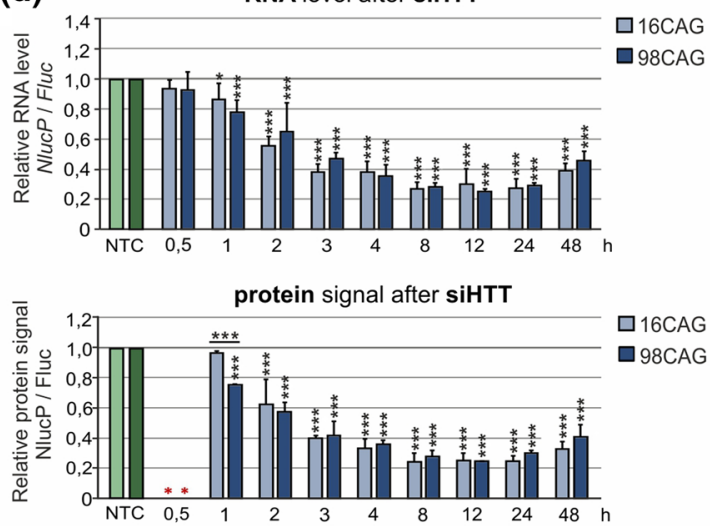

(e)
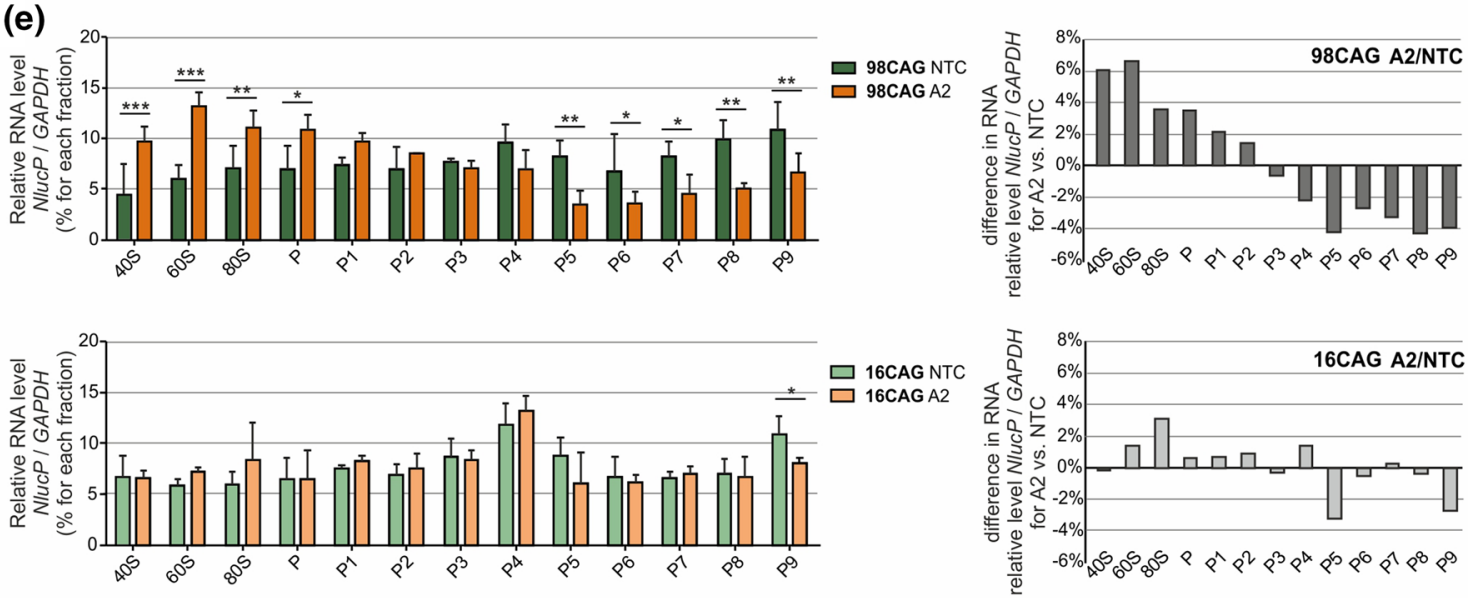

(f)
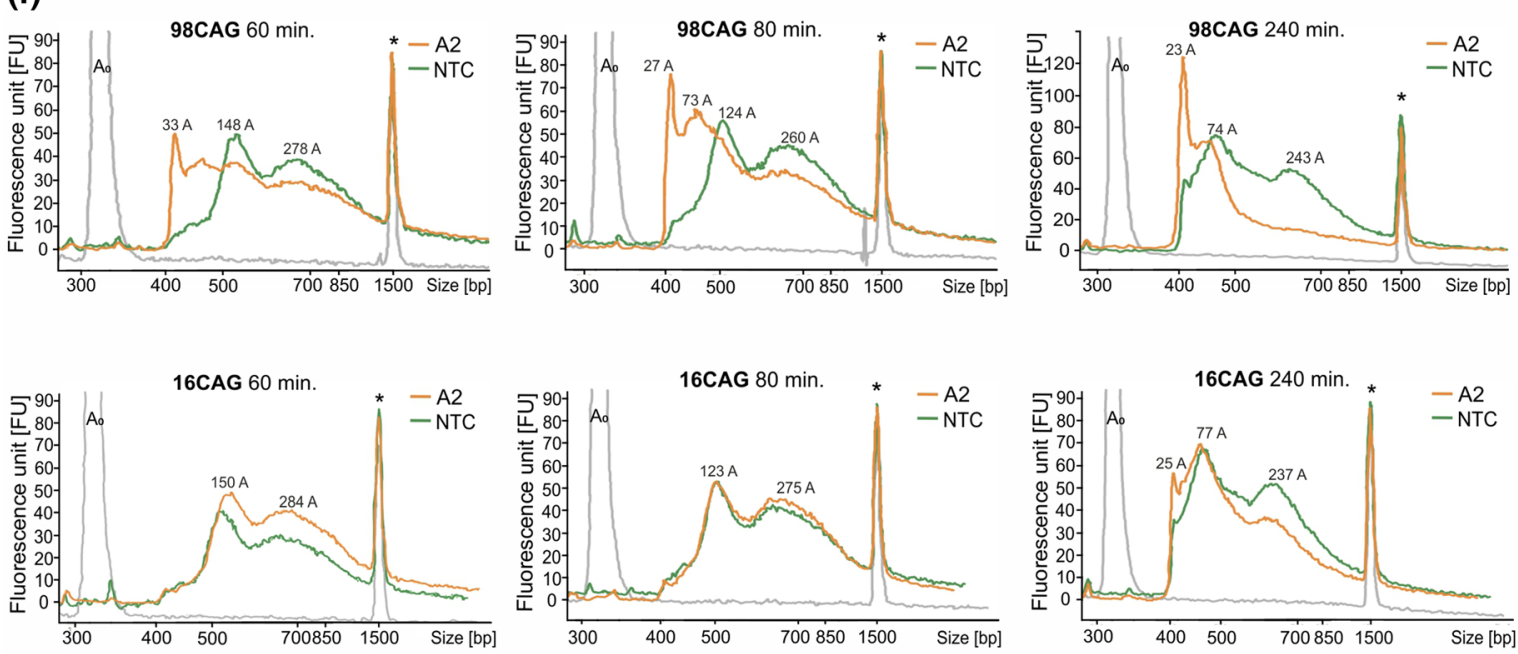
4Fig. 4 Mechanistic details of A2 activity in stable cell lines with inducible expression of the HTT fragment. a Constructs used to generate Flp-In T-REx-293 cell lines with two-directional, inducible expression of the HTT fragment (exon 1 with 16 or 98 CAG repeats) fused with NlucP. Fluc expression was used as a reference. b Timeline of the experiments presented in this figure. Specific treatment and cell lysis time points are indicated. c, d Results of RT-qPCR (upper panels) and dual-luciferase assay (lower panels) to determine the HTT-NlucP transcript level and HTT-NlucP protein signal, respectively, after transfection of the 16CAG and 98CAG cell lines with $100 \mathrm{nM} \mathrm{A} 2$ (c) or siHTT (d) at the indicated time points. The results were normalized to the mRNA level/protein signal of Fluc in the same sample and are shown as the relative expression level/ relative protein signal of HTT-NlucP in cells transfected with $100 \mathrm{nM}$ control siRNA (NTC, siRLuc). $n=3$. e Results of RT-qPCR to assess HTT-NlucP expression levels in the indicated fractions containing ribosomal subunits (40S and 60S), the $80 \mathrm{~S}$ monosome and polysomes (P-P9) after transfection of the 98CAG (upper panels) or $16 \mathrm{CAG}$ (lower panels) cell lines with $100 \mathrm{nM} \mathrm{A} 2$ or control siRNA (NTC, siRLuc) at $3 \mathrm{~h}$ after induction. Data from each fraction were normalized to GAPDH expression and are presented as the \% of HTT-NlucP expression in which $100 \%$ is the sum of the obtained values for all fractions. Graphs in the right panels show data with values calculated as the \% difference in values obtained for separated fractions for control siRNA vs. A2. $n=3$. The data for $\mathbf{c}-\mathbf{e}$ were analyzed using twoway ANOVA. f Analysis of the poly(A) tail length of the HTT-NlucP transcript in the 98CAG (upper panels) or 16CAG (lower panels) cell lines at the indicated time points $(60,80,120 \mathrm{~min})$ after transfection with $100 \mathrm{nM}$ A2 or control siRNA (NTC, siRLuc). Estimated poly(A) tail lengths are indicated. The experiment was repeated $(n=2)$, and similar results were obtained. $A_{0}$ - peak obtained with reporter-specific primers to amplify a region upstream of the polyadenylation site. *An internal standard peak (1500 bp upper marker)

AGO2 (Fig. 5b). Based on previous experiments (Fig. 4c), we selected early time point of $3 \mathrm{~h}$ after the induction of HTT-NlucP expression (Fig. 5a) which we found suitable for analysis of the details of A2 activity. As in previous experiments, in this time point in the 98CAG cell line (Fig. 4c, d), both A2 and siHTT repressed HTT-NlucP expression up to $50 \%$ of control level (Fig. 5c). As expected for the AGO2mut and AGO2del cell lines transfected with typical siRNA, siHTT, repression of HTT-NlucP was completely abolished at both the transcript and protein levels and could be restored after WT AGO2 overexpression (Fig. 5c, blue bars). In contrast, after $\mathrm{A} 2$ transfection into AGO2mut and AGO2del cell lines, efficient lowering of both, transcript and protein levels of HTT-NlucP was achieved (Fig. 5c, orange bars). Additionally, we observed no substantial effects of WT AGO2 overexpression on A2 and siHTT activities. Together, our results show that A2-mediated downregulation of HTT reporter expression is mostly independent of AGO2-mediated slicer activity but is rather a consequence of transcript deadenylation and translation inhibition. Moreover, considering canonical miRNA-related mechanisms, our observations suggest that other AGO proteins (AGO1, AGO3, AGO4) and their respective miRISCs are sufficient in mutant transcript repression caused by $\mathrm{A} 2$, in the absence of $\mathrm{AGO} 2$.

\section{Discussion}

\section{Normal and mutant alleles of polyQ diseases-related genes show varied susceptibility to regulation by art-miRNAs}

Art-miRNAs were designed to target mutation site, i.e. expanded CAG repeat tract, in several transcripts implicated in polyQ diseases $[25,26]$. The main rationale behind such design was to generate the universal treatment for these rare disorders. However, during research we and others (Supplementary Table 1) observed varied susceptibility of targeted transcripts to regulation by art-miRNA (Fig. 1a).

The common feature of polyQ diseases-related mRNAs is their rather low cellular level, including the brain regions mostly affected in polyQ diseases [53]. We confirmed the relatively low expression of four selected genes in patientderived fibroblasts (HTT, ATN1, ATXN3 and ATXN7), however, we also found substantial differences between the quantities of these mRNAs (Fig. 1d). In previously published studies, turnover rate and cellular abundance of transcripts were found to influence the efficiency of downregulation mediated by RNAi [54, 55]. Therefore, these factors might contribute to the observed differences in A2 activity for various transcripts, i.e., higher efficiency of ATN1 silencing may result, at least partially, from higher expression level of this gene.

In addition to the cellular factors, we looked at polyQ disease-related transcripts and noticed that they differ in their arrangement of specific regions as well as the location of the repeat tract within the ORF (Fig. 2a). To address specific questions concerning the impact of CAG repeat tract localization on differences in allele-selective silencing by art-miRNAs, we developed cellular models with exogenous expression of the designed constructs (Fig. 2b). Silencing of exogenes expression may differ from that of endogenes, as higher expression levels of exogenes are obtained, and all additional sequences that could affect silencing efficiency are only present in endogenes. Nevertheless, we observed clear tendencies in the potency of art-miRNAs depending on the location of their targeted site and its flanking sequences (Fig. 2c). Clearly, CAG repeat tract length also determines art-miRNA activity, as large differences were observed for normal and mutant alleles silencing. Moreover, we revealed that it is crucial that the targeted sequence is present in the ORF, as the presence of the targeted tract in the $3^{\prime} \mathrm{UTR}$ caused efficient silencing of both normal and mutant alleles (Fig. 2c). Possibly this preference is caused by the lack of ongoing translation in $3^{\prime}$ UTRs, in contrast to ORF regions where ribosomes interfere with the miRISC complexes [56]. Additionally, unique features of each transcript and the context of the targeted sequence can affect 
(a)

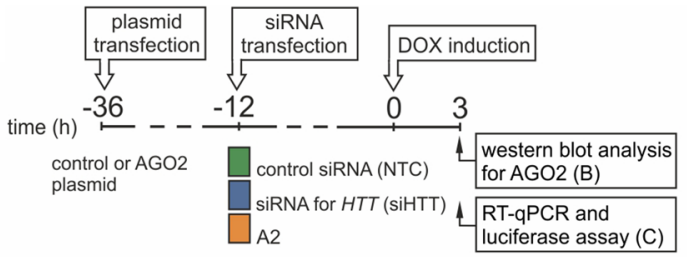

(b)

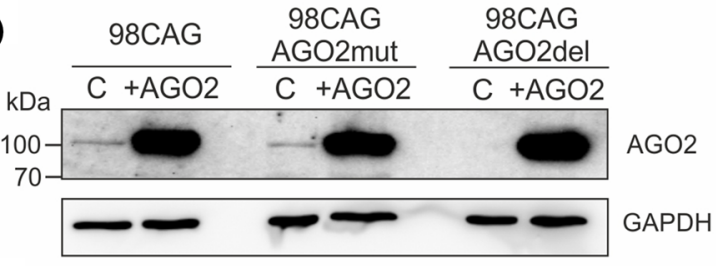

(c)

\begin{tabular}{|l|cccccccccccc|}
\hline control plasmid & + & - & + & - & + & - & + & - & + & - & + & - \\
\hline AGO2 plasmid & - & + & - & + & - & + & - & + & - & + & - & + \\
\hline A2 & + & + & - & - & + & + & - & - & + & + & - & - \\
\hline SiHTT & - & - & + & + & - & - & + & + & - & - & + & + \\
\hline
\end{tabular}
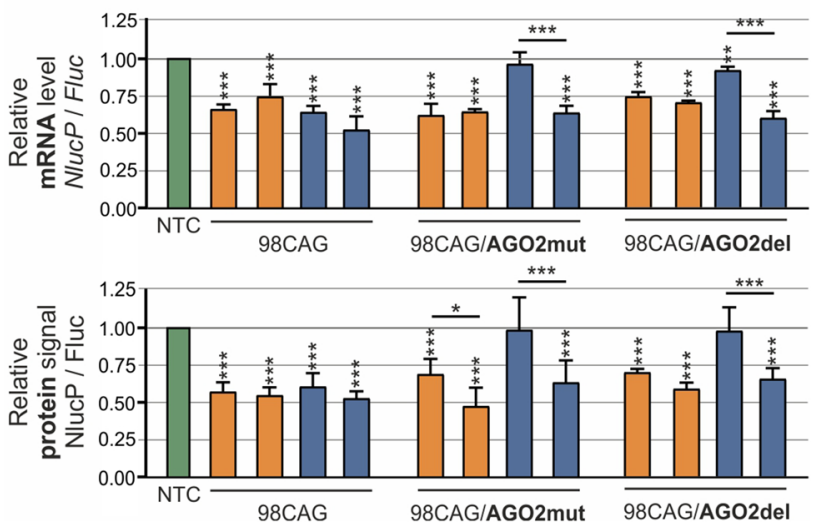

Fig. 5 Verification of the involvement of AGO2 in A2 activity. a Timeline for the experiments presented in this figure. Specific treatment and cell lysis time points are indicated. b Western blot analysis of AGO2 protein levels in 98CAG Flp-In T-REx-293 stable cell lines (98CAG standard cell line, AGO2del deletion of endogenous AGO2, AGO2mut abolished catalytic activity of slicer domain). $+A G O 2$ cell lines after transfection with AGO2 WT plasmid to rescue protein. c Results of RT-qPCR and luciferase assays to detect HTT-NlucP mRNA and protein levels, respectively, after transfection of the 98CAG cell lines (including AGO2mut and AGO2del) with $100 \mathrm{nM}$ A2 or siHTT as well as the indicated plasmids. Data were normalized to Fluc expression levels in the same sample and HTT-NlucP expression levels after transfection with $100 \mathrm{nM}$ control siRNA (NTC, siRLuc). The data were analyzed using two-way ANOVA (with Bonferroni multiple comparisons test among a set of samples for each of the cell lines). $n=3$

efficiency and allele-selectivity of art-miRNAs. One such factor may be the structure formed by the CAG repeat tract, the stability of which was shown in vitro to be dependent on the flanking sequence (reviewed in [57]). Moreover, additional factors, like varying distance of the targeted site from STOP codon or from $3^{\prime}$ and $5^{\prime}$-ends of transcript (Fig. 2a), could contribute to diversity in efficiency of polyQ diseasesrelated genes silencing by A2 $[58,59]$.

\section{Art-miRNAs activate events of mRNA deadenylation and translation inhibition}

MiRNA-mediated regulation is known to occur in many ways depending on the activating miRNA and targeted mRNA, which can affect each other through multiple miRISC components $[60,61]$. As the repertoire of miRISC proteins activate various cellular processes, the detailed analysis of a particular gene silencing mechanism is complex [3, 62]. Briefly, this silencing mechanism involves AGO-mediated recruitment of the GW182/TNRC6 protein family [51, 63], followed by subsequent binding of poly(A)binding protein (PABPC), mRNA deadenylase complexes PAN2-PAN3 and CCR4-NOT, catalyzing deadenylation of the mRNA target, eventually leading to target decapping and transcript degradation ([64-67], reviewed in [2]). We show that art-miRNAs targeting expanded CAG repeats in ORF regions cause translation inhibition (Fig. 4e, top panel) and activate rapid mRNA deadenylation (Fig. 4f, top panel), similarly to classical miRNA pathway. Moreover, mRNA deadenylation and translational repression in typical miRISC-mediated gene silencing were also shown to be interconnected when AGO-miRNAs bound 3'UTRs (reviewed in [3, 62]). Nevertheless, the vast majority of endogenous miRNAs target 3'UTR sequences and cause mRNA decay (estimated at 66-90\%) that is directly responsible for the protein downregulation [62, 68, 69]. In this study, we initially observed stronger lowering of protein level, than mRNA level (Fig. 4c), suggesting that for a pool of transcripts targeted by art-miRNAs in ORF region, translation was inhibited without activation of mRNA decay. However, when we performed detailed poly(A) tail length analysis after A2 art-miRNA treatment, deadenylation was observed already at the earliest time point analyzed after transgene induction (60 min) (Fig. 4f, top panel). On the other hand, our data obtained from polysome profiling suggested that A2-activated translational repression occurs also very rapidly, $3 \mathrm{~h}$ after transgene induction (Fig. 4e, top panel). Therefore, we cannot exclude that deadenylation preceded or was concurrent with translation inhibition. Indeed, in some cases, translational inhibition was shown to precede poly(A) tail shortening and mRNA decay. Such cases were: a study performed in HeLa cells [8] and a study using a Drosophila S2 cell-based controllable expression system [70] where miRNA-targeted sequences were localized in the 3'UTR. Here, to understand the investigated mechanism, it was also crucial to determine if ribosome complexes are formed on targeted transcripts as the result of art-miRNA activity. Our data obtained from polysome profiling suggest that A2-activated translational repression can occur at the 
elongation step and/or at the initiation step (Fig. 4e). This conclusion is supported by the comparison of the shift of HTT transcript, observed after A2 treatment, with the profiles of mRNA distributions in monosome and polysome fractions characteristic for global inhibition of translation at the initiation or elongation step [71, 72].

Transcript-dependent factors, affecting the activation of deadenylation and translation inhibition processes, may also contribute to differences in the effectiveness of artmiRNA in different models of polyQ diseases. According to translation-dependent closed-loop model [73, 74], it can be assumed that, although CAG repeats are in a very large distance from the poly(A) tail (especially for HTT transcript $\sim 13 \mathrm{~kb}$ ), art-miRNA-bound miRISCs are in close proximity to the poly(A) tails of polyQ disease-related mRNAs in cells (Fig. 6). In this case, miRISC-mediated translational repression can also occur through recruitment of the RNA helicase DDX6, which acts as both a translational inhibitor and decapping activator [75-77]. Moreover, it was also shown that DDX6 can act by displacing the eukaryotic translation initiation factors eIF4A-I and eIF4A-II from the targeted transcripts, thereby preventing translation initiation $[10,78$, 79]. These processes are dependent on features of 3'UTR region of targeted transcript, as various cis- and trans-acting elements in specific $3^{\prime} U T R s$ were found to influence miRNA-mediated gene expression regulation [80].

\section{The art-miRNA mechanism as a model for the AGO-dependent cooperative activities of miRNAs within ORF regions}

It is known that miRNAs regulate genes expression mostly by recognition of sites within 3'UTR, however numerous miRNA-binding sites were revealed by global approaches also in the ORFs of human mRNAs [81, 82]. The functionalities of approximately twenty sites of this type in specific transcripts have been experimentally confirmed so far (reviewed in [83]), but precise mechanisms have not been extensively investigated. Recently, a specific type of miRNA recognition elements exclusive to ORF regions was described, and a mechanism of gene expression regulation by temporary ribosome stalling was proposed for DAPK3 kinase [84]. Based on the results of our study, we can extrapolate mechanistic details of ORF regions-targeting by miRNAs, especially when multiple binding sites are present. Indeed, for miRNA-based regulation within ORFs, multiple binding sites have been found frequently [83]. One such example is the regulation of the expression of a family of genes containing $\mathrm{C}_{2} \mathrm{H}_{2}$ zinc-finger domains by a group of miRNAs [85, 86]. Additionally, a general role of repeat tracts localized in ORFs in post-transcriptional regulation was suggested based on predicted interactions [86]. Overall, these data and results regarding art-miRNA activity suggest

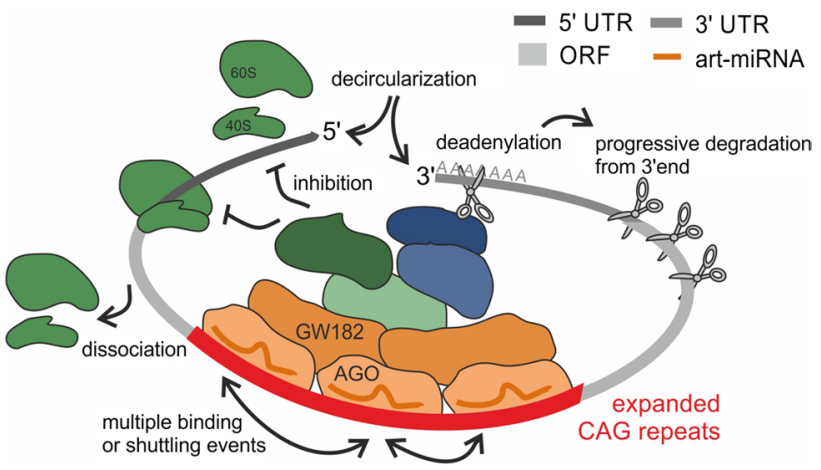

Fig. 6 Model of art-miRNA activity targeting transcripts containing expanded CAG repeat tracts within the ORF region. Art-miRNA loaded into AGO binds to mutant CAG repeat tract with a mismatch formed in the central region of this interaction. Multiple binding or shuttling of the AGO protein results in the formation of the miRISC, which affects translation by the inhibition of its initiation or early elongation. Shortening of the poly(A) tail is activated for a pool of targeted transcripts that leads to the subsequent degradation of mRNA

that for the efficient regulation of a gene's expression by targeting its ORF, multiple binding sites are required, resulting in cooperative action. Some mechanistic details of the cooperative activity of miRNAs were revealed, e.g., a FRETbased method was used to show that $\mathrm{AGO} 2$ dissociation is in kinetic competition with lateral diffusion, resulting in shuttling between adjacent target sites [87].

In general, human cells express four AGO paralogs (AGO1-4) that act to regulate miRNA-based gene expression [88]. AGO2 is the most abundant, as it accounts for $\sim 70 \%$ of the total AGO pool in HEK $293 \mathrm{~T}$ and fibroblast cells $[89,90]$, in which we performed most of mechanistic experiments. Previously, discrimination between the normal and mutant alleles of HTT mRNA by art-miRNAs was reported to be highly sensitive to the cellular pool of AGO2 and GW182 family proteins [30]. Our analysis in total AGO2 knockout and AGO2 D597A endonuclease-deficient cell lines, showed that the absence of AGO2 does not affect the observed silencing activity of exemplary A2 art-miRNA (Fig. 5c). These results suggest that other slicer-deficient AGOs (AGO1, 3 and/or 4) can act in the cooperative repression of the mutant allele. Nevertheless, we do not rule out that AGO2 is a key, most abundant miRISC core protein, but we show it may be replaced by other AGOs. These results are consistent with previous observations that the majority of human miRNAs associate with all four AGOs and do not have a preference for a particular AGO paralog [20, 91, 92]. We assume, that after art-miRNA-AGO complex binding to mRNA, the subsequent co-recruitment of the GW182/ TNRC6 with other effector miRISC proteins results in alleleselective inhibition of the mutant allele. Our data suggest that art-miRNAs can be additionally recruited by slicerdeficient AGO proteins (AGO1, 3 and/or 4) to the expanded 
CAG repeats (Fig. 6) what might turn out to be advantageous for the experimental therapy based on art-miRNA reagents. This is due to the previous RNA-seq and mass spectrometry analysis that clearly indicate that in brain tissue the relative abundance of AGO1, AGO3 and/or AGO4 (when related to the total AGO pool) are higher than in many other cells and tissues analyzed $[89,93]$. This particularly applies to AGO1 protein as quantitative proteomic approach revealed in HEK 293T cells the following proportions of AGO proteins: 17\% $\mathrm{AGO} 1, \sim 75 \% \mathrm{AGO} 2, \sim 6 \% \mathrm{AGO} 3$ and $~ 2 \%$ AGO4, whereas similar mass spectrometry analysis conducted on mouse brain lysates showed proportions: 35\% $\mathrm{AGO} 1, \sim 55 \% \mathrm{AGO} 2, \sim 9 \% \mathrm{AGO} 3$ and $<1 \% \mathrm{AGO} 4$ [89].

\section{Art-miRNA activity in the context of other therapeutic strategies for polyQ diseases}

We are now witnessing large advances in antisense oligonucleotide (ASO)- and RNAi-based strategies in clinical trials $[94,95]$. The most advanced clinical trial of a causative therapy for HD involves the intrathecal delivery of RNase$\mathrm{H}$-activating ASOs targeting HTT (ClinicalTrials.gov Identifier: NCT03842969). The results obtained thus far are very promising, as a decrease in huntingtin in the spinocerebellar fluid was reported [96]. Nevertheless, many challenges remain to be faced in the developed therapy, among which the allele-selectivity of silencing is one of the major points [97]. Preservation of the level of the normal allele might be required, as its long-term downregulation, which would be the result of long-term treatment, could have many adverse effects [98, 99]. Additionally, in the case of HD, some reports suggest that targeting exon 1 of $H T T$, which contains the CAG tract, may be crucial to eliminate key toxic entities causing HD pathogenesis $[100,101]$. For these reasons, we find an approach using art-miRNAs to be desirable. This CAG repeat-targeting strategy offers an option for the preferential silencing of several mutant alleles responsible for polyQ diseases and would be applicable to a larger group of patients than an allele-selective SNP-targeting-based approach. Moreover, due to somatic instability, mosaicism of highly expanded CAG repeats in the brain is likely a common effect largely responsible for brain-specific pathology, as shown in HD [102-104]. In this case, transcripts containing increasingly expanded CAG repeat tracts are expected to be more efficiently targeted by art-miRNAs. This assumption remains to be proven experimentally but would clearly allow preferential targeting of the RNAs which translation leads to pathogenesis.

The potential universality of targeting the mutation site in RNA was also shown for the activity of ASOs acting as translation blockers or splicing modulators that were tested for several polyQ diseases [105-107]. According to recent findings, an art-miRNA-based therapeutic strategy might not be applicable for SCA1 [108], and the development of a universal molecule for several polyQ diseases might require further research. Although more demanding than initially assumed, the applicability of this strategy in at least a few disorders remains feasible. Art-miRNAs possess additional advantages as they can be chemically modified $[31,38]$ or expressed from vectors [33, 109], and can include application of novel approaches for delivery to the brain [110, 111]. Interestingly, CRISPR-Cas9- and ZFP-based CAG repeat-targeting strategies were recently successfully tested in HD models [112-116]. These approaches offer an alternative solution for mutant HTT inhibition after the binding of specifically designed molecules to mutant DNA, but some challenges remain before their clinical testing.

In summary, our model of art-miRNAs activity show potential versatility in the miRNA-based regulation of gene expression. Although this model (Fig. 6) is based on results obtained for artificial miRNA, it contributes to a better understanding of the mechanisms of action of natural miRNAs which interact with sequences located in ORFs with adjacent multiple binding sites. These mechanisms have been harnessed to activate the therapeutically beneficial silencing of mutant genes with CAG repeat expansions, showing the great flexibility of RNAi-based mechanisms in cells.

Acknowledgements This work was supported by Grants from National Science Centre [2014/15/B/NZ1/01880 to WJK/AF, 2015/17/D/ NZ5/03443 to AF, 2015/19/B/NZ2/02453 to WJK/ACie, 2015/17/N/ NZ2/01916 to EK]; and Polish Ministry of Science and Higher Education [DI 2011027841 to ASC and 01/KNOW2/2014, the KNOW program]. Microscopic images were obtained in the Laboratory of Subcellular Structures Analysis, IBCH PAS. The authors would like to thank former and current members of the Department for discussions and contributions to the preliminary analyses of this study.

Author contributions Conceptualization: WJK, AF, ACie and ASC. Transfections and western blot on fibroblasts: AF, ASC and DZ. DdPCR: AF and MWW. Design of luciferase-based plasmids, relevant experiments and bioinformatics analyses of transcripts features: ASC. Design of luciferase-based plasmids used for Flp-In T-REx cell line generation, luciferase assay experiments: ACie. Flp-In cell lines, RTqPCR and poly(A) tail length assay experiments: ACie, PJ. Optimization of polysome profiling method: ACio, KDR and DZ. Polysome profiling experiments and relevant RT-qPCR: ACio. Generation of NPs and relevant smFISH: EK. SmFISH on fibroblasts: MM. AGO2 mutant and knockout cell lines: MD, MO and ACie. Manuscript writing: AF, ASC and ACie, with the input and revision from all authors.

\section{Compliance with ethical standards}

Conflict of interest The authors declare that the research was conducted in the absence of any commercial or financial relationships that could be construed as a potential conflict of interest.

Open Access This article is licensed under a Creative Commons Attribution 4.0 International License, which permits use, sharing, adaptation, distribution and reproduction in any medium or format, as long 
as you give appropriate credit to the original author(s) and the source, provide a link to the Creative Commons licence, and indicate if changes were made. The images or other third party material in this article are included in the article's Creative Commons licence, unless indicated otherwise in a credit line to the material. If material is not included in the article's Creative Commons licence and your intended use is not permitted by statutory regulation or exceeds the permitted use, you will need to obtain permission directly from the copyright holder. To view a copy of this licence, visit http://creativecommons.org/licenses/by/4.0/.

\section{References}

1. Sonenberg N, Fabian MR (2012) The mechanics of miRNAmediated gene silencing: a look under the hood of miRISC. Nat Struct Mol Biol 19:586-593. https://doi.org/10.1038/nsmb.2296

2. Stroynowska-Czerwinska A, Fiszer A, Krzyzosiak WJ (2014) The panorama of miRNA-mediated mechanisms in mammalian cells. Cell Mol Life Sci 71:2253-2270. https://doi.org/10.1007/ s00018-013-1551-6

3. Jonas S, Izaurralde E (2015) Towards a molecular understanding of microRNA-mediated gene silencing. Nat Rev Genet 16:421433. https://doi.org/10.1038/nrg3965

4. Bartel DP (2018) Metazoan MicroRNAs. Cell 173:20-51. https ://doi.org/10.1016/J.CELL.2018.03.006

5. Elbashir SM, Harborth J, Lendeckel W et al (2001) Duplexes of 21-nucleotide RNAs mediate RNA interference in cultured mammalian cells. Nature 411:494-498

6. Pillai RS, Bhattacharyya SN, Artus CG et al (2005) Inhibition of translational initiation by Let-7 MicroRNA in human cells. Science 309:1573-1576. https://doi.org/10.1126/science.11150 79

7. Eulalio A, Huntzinger E, Nishihara T et al (2009) Deadenylation is a widespread effect of miRNA regulation. RNA 15:21-32. https://doi.org/10.1261/rna.1399509

8. Béthune J, Artus-Revel CG, Filipowicz W (2012) Kinetic analysis reveals successive steps leading to miRNA-mediated silencing in mammalian cells. EMBO Rep 13:716-723. https://doi. org/10.1038/embor.2012.82

9. Huntzinger E, Kuzuoglu-Öztürk D, Braun JE et al (2013) The interactions of GW182 proteins with PABP and deadenylases are required for both translational repression and degradation of miRNA targets. Nucleic Acids Res 41:978-994. https://doi. org/10.1093/nar/gks1078

10. Meijer HA, Kong YW, Lu WT et al (2013) Translational repression and eIF4A2 activity are critical for microRNAmediated gene regulation. Science 340:82-85. https://doi. org/10.1126/science.1231197

11. Duursma AM, Kedde M, Schrier M et al (2008) miR-148 targets human DNMT3b protein coding region. RNA 14:872-877. https://doi.org/10.1261/rna.972008

12. Forman JJ, Legesse-Miller A, Coller HA (2008) A search for conserved sequences in coding regions reveals that the let-7 microRNA targets Dicer within its coding sequence. Proc Natl Acad Sci USA 105:14879-14884

13. Tay Y, Zhang J, Thomson AM et al (2008) MicroRNAs to Nanog, Oct4 and Sox 2 coding regions modulate embryonic stem cell differentiation. Nature 455:1124-1128

14. Elcheva I, Goswami S, Noubissi FK, Spiegelman VS (2009) CRD-BP protects the coding region of betaTrCP1 mRNA from miR-183-mediated degradation. Mol Cell 35:240-246. https:// doi.org/10.1016/j.molcel.2009.06.007
15. Forman JJ, Coller HA (2010) The code within the code: MicroRNAs target coding regions. Cell Cycle 9:1533-1541. https:// doi.org/10.4161/cc.9.8.11202

16. Jopling CL, Yi M, Lancaster AM et al (2005) Modulation of hepatitis $\mathrm{C}$ virus RNA abundance by a liver-specific MicroRNA. Science 309:1577-1581. https://doi.org/10.1126/scien ce. 1113329

17. Ørom UA, Nielsen FC, Lund AH (2008) MicroRNA-10a binds the 5'UTR of ribosomal protein mRNAs and enhances their translation. Mol Cell 30:460-471. https://doi.org/10.1016/j. molcel.2008.05.001

18. Tsai N-P, Lin Y-L, Wei L-N (2009) MicroRNA mir-346 targets the 5 '-untranslated region of receptor-interacting protein 140 (RIP140) mRNA and up-regulates its protein expression. Biochem J 424:411-418. https://doi.org/10.1042/BJ20090915

19. Gu S, Jin L, Zhang F et al (2009) The biological basis for microRNA target restriction to the 3' untranslated region in mammalian mRNAs. Nat Struct Mol Biol 16:144-150. https ://doi.org/10.1038/nsmb.1552.The

20. Broderick JA, Salomon WE, Ryder SP et al (2011) Argonaute protein identity and pairing geometry determine cooperativity in mammalian RNA silencing. RNA 17:1858-1869. https://doi. org/10.1261/rna.2778911.promotes

21. Grimson A, Farh KK-H, Johnston WK et al (2007) MicroRNA targeting specificity in mammals: determinants beyond seed pairing. Mol Cell 27:91-105

22. Saetrom P, Heale BSE, Snøve O et al (2007) Distance constraints between microRNA target sites dictate efficacy and cooperativity. Nucleic Acids Res 35:2333-2342

23. Orr HT (2012) Polyglutamine neurodegeneration: expanded glutamines enhance native functions. Curr Opin Genet Dev 22:251-255

24. Stoyas CA, La Spada AR (2018) The CAG-polyglutamine repeat diseases: a clinical, molecular, genetic, and pathophysiologic nosology. In: Handbook of clinical neurology. pp 143170. https://doi.org/10.1016/B978-0-444-63233-3.00011-7

25. Matsui M, Corey DR (2012) Allele-selective inhibition of trinucleotide repeat genes. Drug Discov Today 17:443-450

26. Fiszer A, Krzyzosiak WJ (2014) Oligonucleotide-based strategies to combat polyglutamine diseases. Nucleic Acids Res 42:67876810. https://doi.org/10.1093/nar/gku385

27. Hu J, Liu J, Corey DR (2010) Allele-selective inhibition of huntingtin expression by switching to an miRNA-like RNAi mechanism. Chem Biol 17:1183-1188

28. Fiszer A, Mykowska A, Krzyzosiak WJ (2011) Inhibition of mutant huntingtin expression by RNA duplex targeting expanded CAG repeats. Nucleic Acids Res 39:5578-5585

29. Hu J, Gagnon KT, Liu J et al (2011) Allele-selective inhibition of ataxin-3 (ATX3) expression by antisense oligomers and duplex RNAs. Biol Chem 392:315-325

30. Hu J, Liu J, Yu D et al (2012) Mechanism of allele-selective inhibition of huntingtin expression by duplex RNAs that target CAG repeats: function through the RNAi pathway. Nucleic Acids Res 40:11270-11280. https://doi.org/10.1093/nar/gks907

31. Yu D, Pendergraff H, Liu J et al (2012) Single-stranded RNAs use RNAi to potently and allele-selectively inhibit mutant huntingtin expression. Cell 150:895-908. https://doi.org/10.1016/j. cell.2012.08.002

32. Aiba Y, Hu J, Liu J et al (2013) Allele-selective inhibition of huntingtin and ataxin-3 expression by RNA duplexes containing unlocked nucleic acid (UNA) substitutions. Biochemistry 52:9329-9338. https://doi.org/10.1021/bi4014209

33. Fiszer A, Olejniczak M, Galka-Marciniak P et al (2013) Selfduplexing CUG repeats selectively inhibit mutant huntingtin expression. Nucleic Acids Res 41:10426-10437. https://doi. org/10.1093/nar/gkt825 
34. Liu J, Pendergraff H, Narayanannair KJ et al (2013) RNA duplexes with abasic substitutions are potent and allele-selective inhibitors of huntingtin and ataxin-3 expression. Nucleic Acids Res 41:8788-8801. https://doi.org/10.1093/nar/gkt594

35. Liu J, Yu D, Aiba Y et al (2013) ss-siRNAs allele selectively inhibit ataxin-3 expression: multiple mechanisms for an alternative gene silencing strategy. Nucleic Acids Res 41:9570-9583. https://doi.org/10.1093/nar/gkt693

36. Hu J, Liu J, Yu D et al (2014) Exploring the effect of sequence length and composition on allele-selective inhibition of human huntingtin expression by single-stranded silencing RNAs. Nucleic Acid Ther. https://doi.org/10.1089/nat.2013.0476

37. Hu J, Liu J, Narayanannair KJ et al (2014) Allele-selective inhibition of mutant Atrophin-1 expression by duplex and single-stranded RNAs. Biochemistry 53:4510-4518. https://doi. org/10.1021/bi500610r

38. Fiszer A, Ellison-Klimontowicz ME, Krzyzosiak WJ (2016) Silencing of genes responsible for polyQ diseases using chemically modified single-stranded siRNAs. Acta Biochim Pol. https ://doi.org/10.18388/abp.2016_1336

39. Fiszer A, Wroblewska J, Nowak B, Krzyzosiak W (2016) Mutant CAG repeats effectively targeted by RNA interference in SCA7 cells. Genes (Basel) 7:132. https://doi.org/10.3390/genes71201 32

40. Urbanek MO, Fiszer A, Krzyzosiak WJ (2017) Reduction of Huntington's disease RNA foci by CAG repeat-targeting reagents. Front Cell Neurosci 11:82. https://doi.org/10.3389/fncel .2017 .00082

41. Takahashi N, Sasagawa N, Suzuki K, Ishiura S (1999) Synthesis of long trinucleotide repeats in vitro. Neurosci Lett 262:45-48. https://doi.org/10.1016/s0304-3940(99)00031-2

42. Figura G, Koscianska E, Krzyzosiak W (2015) In vitro expansion of CAG, CAA, and mixed CAG/CAA repeats. Int J Mol Sci 16:18741-18751. https://doi.org/10.3390/ijms160818741

43. Sammarco MC, Grabczyk E (2005) A series of bidirectional tetracycline-inducible promoters provides coordinated protein expression. Anal Biochem 346:210-216. https://doi. org/10.1016/j.ab.2005.08.033

44. Suzuki K, Bose P, Leong-Quong RY et al (2010) REAP: a two minute cell fractionation method. BMC Res Notes 3:294. https ://doi.org/10.1186/1756-0500-3-294

45. Faye MD, Graber TE, Holcik M (2014) Assessment of selective mRNA translation in mammalian cells by polysome profiling. $\mathrm{J}$ Vis Exp. https://doi.org/10.3791/52295

46. Blair JD, Hockemeyer D, Doudna JA et al (2017) Widespread translational remodeling during human neuronal differentiation. Cell Rep 21:2005-2016. https://doi.org/10.1016/j.celre p.2017.10.095

47. Kusov YY, Shatirishvili G, Dzagurov G, Gauss-Müller V (2001) A new G-tailing method for the determination of the poly(A) tail length applied to hepatitis A virus RNA. Nucleic Acids Res 29:E57-E67. https://doi.org/10.1093/nar/29.12.e57

48. Meister G, Landthaler M, Patkaniowska A et al (2004) Human Argonaute 2 mediates RNA cleavage targeted by miRNAs and siRNAs. Mol Cell 15:185-197. https://doi.org/10.1016/j.molce 1.2004.07.007

49. Gu S, Jin L, Zhang F et al (2009) Biological basis for restriction of microRNA targets to the 3' untranslated region in mammalian mRNAs. Nat Struct Mol Biol 16:144-150. https://doi. org/10.1038/nsmb.1552

50. Didiot M-C, Ferguson CM, Ly S et al (2018) Nuclear localization of huntingtin mRNA is specific to cells of neuronal origin. Cell Rep 24:2553-2560.e5. https://doi.org/10.1016/j.celre p.2018.07.106
51. Liu J, Carmell MA, Rivas FV et al (2004) Argonaute2 is the catalytic engine of mammalian RNAi. Science (80-) 305:1437-1441

52. Rivas FV, Tolia NH, Song JJ et al (2005) Purified Argonaute2 and an siRNA form recombinant human RISC. Nat Struct Mol Biol 12:340-349

53. Hawrylycz MJ, Lein ES, Guillozet-Bongaarts AL et al (2012) An anatomically comprehensive atlas of the adult human brain transcriptome. Nature 489:391-399. https://doi.org/10.1038/ nature 11405

54. Larsson E, Sander C, Marks D (2010) mRNA turnover rate limits siRNA and microRNA efficacy. Mol Syst Biol 6:433. https://doi. org/10.1038/msb.2010.89

55. Hong SW, Jiang Y, Kim S et al (2014) Target gene abundance contributes to the efficiency of siRNA-mediated gene silencing. Nucleic Acid Ther 24:192. https://doi.org/10.1089/ NAT.2013.0466

56. Gu W, Xu Y, Xie X et al (2014) The role of RNA structure at $5^{\prime}$ untranslated region in microRNA-mediated gene regulation. RNA 20:1369-1375. https://doi.org/10.1261/rna.044792.114

57. Ciesiolka A, Jazurek M, Drazkowska K, Krzyzosiak WJ (2017) Structural characteristics of simple RNA repeats associated with disease and their deleterious protein interactions. Front Cell Neurosci 11:97. https://doi.org/10.3389/fncel.2017.00097

58. Fang Z, Rajewsky N (2011) The impact of miRNA target sites in coding sequences and in 3'UTRs. PLoS ONE 6:e18067. https ://doi.org/10.1371/journal.pone.0018067

59. Duchaine TF, Fabian MR (2019) Mechanistic insights into MicroRNA-mediated gene silencing. Cold Spring Harb Perspect Biol 11:a032771. https://doi.org/10.1101/cshperspect.a032771

60. Kalantari R, Hicks JA, Li L et al (2016) Stable association of RNAi machinery is conserved between the cytoplasm and nucleus of human cells. RNA. https://doi.org/10.1261/rna.05649 9.116

61. Trabucchi M (2019) Subcellular Heterogeneity of the microRNA Machinery. Trends Genet 35:15-28. https://doi.org/10.1016/J. TIG.2018.10.006

62. Gebert LFR, MacRae IJ (2019) Regulation of microRNA function in animals. Nat Rev Mol Cell Biol 20:21-37. https://doi. org/10.1038/s41580-018-0045-7

63. Rehwinkel J, Behm-Ansmant I, Gatfield D, Izaurralde E (2005) A crucial role for GW182 and the DCP1:DCP2 decapping complex in miRNA-mediated gene silencing. RNA 11:1640-1647. https ://doi.org/10.1261/rna.2191905

64. Behm-Ansmant I, Rehwinkel J, Doerks T et al (2006) mRNA degradation by miRNAs and GW182 requires both CCR4:NOT deadenylase and DCP1:DCP2 decapping complexes. Genes Dev 20:1885-1898. https://doi.org/10.1101/gad.1424106

65. Braun JE, Huntzinger E, Fauser M, Izaurralde E (2011) GW182 proteins directly recruit cytoplasmic deadenylase complexes to miRNA targets. Mol Cell 44:120-133. https://doi.org/10.1016/j. molcel.2011.09.007

66. Chekulaeva M, Mathys H, Zipprich JT et al (2011) miRNA repression involves GW182-mediated recruitment of CCR4-NOT through conserved W-containing motifs. Nat Struct Mol Biol 18:1218-1226. https://doi.org/10.1038/nsmb.2166

67. Fabian MR, Cieplak MK, Frank F et al (2011) miRNA-mediated deadenylation is orchestrated by GW182 through two conserved motifs that interact with CCR4-NOT. Nat Struct Mol Biol 18:1211-1217. https://doi.org/10.1038/nsmb.2149

68. Guo H, Ingolia NT, Weissman JS, Bartel DP (2010) Mammalian microRNAs predominantly act to decrease target mRNA levels. Nature 466:835-840

69. Eichhorn SWW, Guo H, McGeary SEE et al (2014) mRNA destabilization is the dominant effect of mammalian MicroRNAs by 
the time substantial repression ensues. Mol Cell 56:104-115. https://doi.org/10.1016/j.molcel.2014.08.028

70. Djuranovic S, Nahvi A, Green R (2012) miRNA-mediated gene silencing by translational repression followed by mRNA deadenylation and decay. Science (80-) 336:237-240. https://doi. org/10.1126/science.1215691

71. Li CH, Ohn T, Ivanov $\mathrm{P}$ et al (2010) eIF5A promotes translation elongation, polysome disassembly and stress granule assembly. PLoS ONE 5:e9942. https://doi.org/10.1371/journal.pone.00099 42

72. Chassé H, Boulben S, Costache V et al (2017) Analysis of translation using polysome profiling. Nucleic Acids Res 45:gkw07. https://doi.org/10.1093/nar/gkw907

73. Vicens Q, Kieft JS, Rissland OS (2018) Revisiting the closedloop model and the nature of mRNA 5' -3 ' communication. Mol Cell 72:805-812

74. Fakim H, Fabian MR (2019) Communication is key: 5'-3' interactions that regulate mRNA translation and turnover. Adv Exp Med Biol 1203:149-164. https://doi.org/10.1007/978-3-03031434-7_6

75. Mathys H, Basquin J, Ozgur S et al (2014) Structural and biochemical insights to the role of the CCR4-NOT complex and DDX6 ATPase in MicroRNA repression. Mol Cell 54:751-765. https://doi.org/10.1016/j.molcel.2014.03.036

76. Rouya C, Siddiqui N, Morita M et al (2014) Human DDX6 effects miRNA-mediated gene silencing via direct binding to CNOT1. RNA 20:1398-1409. https://doi.org/10.1261/rna.04530 2.114

77. Kamenska A, Simpson C, Vindry C et al (2016) The DDX6-4E-T interaction mediates translational repression and P-body assembly. Nucleic Acids Res 44:6318-6334. https://doi.org/10.1093/ nar/gkw565

78. Fukao A, Mishima Y, Takizawa N et al (2014) MicroRNAs trigger dissociation of eIF4AI and eIF4AII from target mRNAs in humans. Mol Cell 56:79-89. https://doi.org/10.1016/j.molce 1.2014.09.005

79. Fukaya T, Iwakawa H-O, Tomari Y (2014) MicroRNAs block assembly of eIF4F translation initiation complex in Drosophila. Mol Cell 56:67-78. https://doi.org/10.1016/j.molcel.2014.09.004

80. Matoulkova E, Michalova E, Vojtesek B, Hrstka R (2012) The role of the $3^{\prime}$ untranslated region in post-transcriptional regulation of protein expression in mammalian cells. RNA Biol 9:563576. https://doi.org/10.4161/rna.20231

81. Hafner M, Landthaler M, Burger L et al (2010) Transcriptomewide identification of RNA-binding protein and microRNA target sites by PAR-CLIP. Cell 141:129-141. https://doi.org/10.1016/j. cell.2010.03.009

82. Helwak A, Kudla G, Dudnakova T, Tollervey D (2013) Mapping the human miRNA interactome by CLASH reveals frequent noncanonical binding. Cell 153:654-665. https://doi.org/10.1016/j. cell.2013.03.043

83. Brümmer A, Hausser J (2014) MicroRNA binding sites in the coding region of mRNAs: extending the repertoire of post-transcriptional gene regulation. BioEssays 36:617-626. https://doi. org/10.1002/bies.201300104

84. Zhang K, Zhang X, Cai Z et al (2018) A novel class of microRNA-recognition elements that function only within open reading frames. Nat Struct Mol Biol 25:1019-1027. https://doi. org/10.1038/s41594-018-0136-3

85. Huang S, Wu S, Ding J et al (2010) MicroRNA-181a modulates gene expression of zinc finger family members by directly targeting their coding regions. Nucleic Acids Res 38:7211-7218. https ://doi.org/10.1093/nar/gkq564

86. Schnall-Levin M, Rissland OS, Johnston WK et al (2011) Unusually effective microRNA targeting within repeat-rich coding regions of mammalian mRNAs. Genome Res 21:1395-1403. https://doi.org/10.1101/gr.121210.111

87. Chandradoss SD, Schirle NT, Szczepaniak M et al (2015) A dynamic search process underlies MicroRNA targeting. Cell 162:96-107. https://doi.org/10.1016/j.cell.2015.06.032

88. Dueck A, Meister G (2014) Assembly and function of small RNA-Argonaute protein complexes. Biol Chem. https://doi. org/10.1515/hsz-2014-0116

89. Hauptmann J, Schraivogel D, Bruckmann A et al (2015) Biochemical isolation of Argonaute protein complexes by AgoAPP. Proc Natl Acad Sci USA 112:11841-11845. https://doi. org/10.1073/pnas.1506116112

90. Völler D, Linck L, Bruckmann A et al (2016) Argonaute family protein expression in normal tissue and cancer entities. PLoS ONE 11:e0161165. https://doi.org/10.1371/journal.pone.01611 65

91. Dueck A, Ziegler C, Eichner A et al (2012) microRNAs associated with the different human Argonaute proteins. Nucleic Acids Res 40:9850-9862. https://doi.org/10.1093/nar/gks705

92. Wang D, Zhang Z, O'Loughlin E et al (2012) Quantitative functions of Argonaute proteins in mammalian development. Genes Dev 26:693-704. https://doi.org/10.1101/gad.182758.111

93. Uhlen M, Fagerberg L, Hallstrom BM et al (2015) Tissue-based map of the human proteome. Science (80-) 347:12604191260419. https://doi.org/10.1126/science.1260419

94. Shen X, Corey DR (2018) Chemistry, mechanism and clinical status of antisense oligonucleotides and duplex RNAs. Nucleic Acids Res 46:1584-1600. https://doi.org/10.1093/nar/gkx1239

95. Setten RL, Rossi JJ, Han S (2019) The current state and future directions of RNAi-based therapeutics. Nat Rev Drug Discov 18:421-446. https://doi.org/10.1038/s41573-019-0017-4

96. Tabrizi SJ, Leavitt BR, Landwehrmeyer GB et al (2019) Targeting huntingtin expression in patients with Huntington's disease. N Engl J Med. https://doi.org/10.1056/NEJMoa1900907

97. Wild EJ, Tabrizi SJ (2017) Therapies targeting DNA and RNA in Huntington's disease. Lancet Neurol 16:837-847. https://doi. org/10.1016/S1474-4422(17)30280-6

98. Saudou F, Humbert S (2016) The biology of huntingtin. Neuron 89:910-926. https://doi.org/10.1016/j.neuron.2016.02.003

99. Liu J-P, Zeitlin SO (2017) Is huntingtin dispensable in the adult brain? J Huntingtons Dis 6:1-17. https://doi.org/10.3233/JHD170235

100. Neueder A, Landles C, Ghosh R et al (2017) The pathogenic exon 1 HTT protein is produced by incomplete splicing in Huntington's disease patients. Sci Rep 7:1307. https://doi.org/10.1038/ s41598-017-01510-z

101. Franich NR, Hickey MA, Zhu C et al (2019) Phenotype onset in Huntington's disease knock-in mice is correlated with the incomplete splicing of the mutant huntingtin gene. J Neurosci Res 97:jnr24493. https://doi.org/10.1002/jnr.24493

102. Telenius H, Kremer B, Goldberg YP et al (1994) Somatic and gonadal mosaicism of the Huntington disease gene CAG repeat in brain and sperm. Nat Genet 6:409-414. https://doi. org/10.1038/ng0494-409

103. Kennedy L, Evans E, Chen C-M et al (2003) Dramatic tissuespecific mutation length increases are an early molecular event in Huntington disease pathogenesis. Hum Mol Genet 12:33593367. https://doi.org/10.1093/hmg/ddg352

104. Wright GEB, Collins JA, Kay C et al (2019) Length of uninterrupted CAG, independent of polyglutamine size, results in increased somatic instability, hastening onset of huntington disease. Am J Hum Genet 104:1116-1126. https://doi.org/10.1016/j. ajhg.2019.04.007

105. Hu J, Matsui M, Gagnon KT et al (2009) Allele-specific silencing of mutant huntingtin and ataxin-3 genes by targeting expanded 
CAG repeats in mRNAs. Nat Biotechnol 27:478-484. https://doi. org/10.1038/nbt.1539

106. Datson NA, González-Barriga A, Kourkouta E et al (2017) The expanded CAG repeat in the huntingtin gene as target for therapeutic RNA modulation throughout the HD mouse brain. PLoS ONE 12:e0171127. https://doi.org/10.1371/journal.pone.01711 27

107. Kourkouta E, Weij R, González-Barriga A et al (2019) Suppression of mutant protein expression in SCA3 and SCA1 mice using a CAG repeat-targeting antisense oligonucleotide. Mol Ther Nucleic Acids 17:601-614. https://doi.org/10.1016/j. omtn.2019.07.004

108. Hu J, Corey DR (2019) Limits of using oligonucleotides for allele-selective inhibition at trinucleotide repeat sequences-targeting the CAG repeat within ataxin-1. Nucleosides Nucleotides Nucleic Acids. https://doi.org/10.1080/15257770.2019.1671592

109. Kotowska-Zimmer A, Ostrovska Y, Olejniczak M (2020) Universal RNAi triggers for the specific inhibition of mutant huntingtin, atrophin-1, ataxin-3, and ataxin-7 expression. Mol Ther Nucleic Acids 19:562-571. https://doi.org/10.1016/j.omtn.2019.12.012

110. Chan KY, Jang MJ, Yoo BB et al (2017) Engineered AAVs for efficient noninvasive gene delivery to the central and peripheral nervous systems. Nat Neurosci 20:1172-1179. https://doi. org/10.1038/nn.4593

111. Alterman JF, Godinho BMDC, Hassler MR et al (2019) A divalent siRNA chemical scaffold for potent and sustained modulation of gene expression throughout the central nervous system. Nat Biotechnol 37:884-894. https://doi.org/10.1038/s4158 7-019-0205-0
112. Monteys AM, Ebanks SA, Keiser MS, Davidson BL (2017) CRISPR/Cas9 editing of the mutant huntingtin allele in vitro and in vivo. Mol Ther 25:12-23. https://doi.org/10.1016/j.ymthe .2016.11.010

113. Yang S, Chang R, Yang H et al (2017) CRISPR/Cas9-mediated gene editing ameliorates neurotoxicity in mouse model of Huntington's disease. J Clin Invest 127:2719-2724. https://doi. org/10.1172/JCI92087

114. Zeitler B, Froelich S, Marlen K et al (2019) Allele-selective transcriptional repression of mutant HTT for the treatment of Huntington's disease. Nat Med. https://doi.org/10.1038/s4159 1-019-0478-3

115. Dabrowska M, Juzwa W, Krzyzosiak WJ, Olejniczak M (2018) Precise excision of the CAG tract from the huntingtin gene by Cas9 nickases. Front Neurosci 12:75. https://doi.org/10.3389/ FNINS.2018.00075

116. Dabrowska M, Ciolak A, Kozlowska E et al (2020) Generation of new isogenic models of Huntington's disease using CRISPRCas9 technology. Int J Mol Sci 21:1854. https://doi.org/10.3390/ ijms 21051854

Publisher's Note Springer Nature remains neutral with regard to jurisdictional claims in published maps and institutional affiliations. 